\title{
Komatiites II: Experimental and Theoretical Investigations of Post-emplacement Cooling and Crystallization
}

\author{
by J. STEWART TURNER, ${ }^{1}$ HERBERT E. HUPPERT, ${ }^{2}$ AND \\ R. STEPHEN J. SPARKS ${ }^{3}$
}

${ }^{1}$ Research School of Earth Sciences, Australian National University, Canberra 2601, Australia ${ }^{2}$ Department of Applied Mathematics and Theoretical Physics, University of Cambridge, Cambridge CB3 9EW

${ }^{3}$ Department of Earth Sciences, University of Cambridge, Cambridge CB2 $3 E Q$

(Received 9 October 1984; revised 25 July 1985)

\begin{abstract}
A BSTRACT
When komatiite lavas are emplaced on the sea floor most of the heat transfer occurs through the upper lava-seawater boundary. We have investigated the cooling and crystallization of komatiites using a series of analogue laboratory experiments with aqueous solutions and by theoretical analysis. In komatiites the viscosity is sufficiently low that convection occurs in the interior of the flow and these motions, due both to thermal and compositional variations, have an important influence on the characteristic features of komatiites such as the strong compositional and textural layering.

The experiments have been conducted with crystallizing aqueous solutions which display the same overall dynamical processes as solidifying komatiites. The solutions used are simple eutectic systems having the property that crystallization from a solution which is substantially more concentrated than the eutectic composition leaves behind residual fiuid which is less dense than the original fluid. This models the decrease in density of komatiite melts on cooling, due to the crystallization of olivine. Such solutions have been cooled strongly through the metal roof of an otherwise insulated container, using a typical fluid depth of $80 \mathrm{~mm}$. Dendritic crystals grew down vertically from the roof and released light fluid, depleted in solute, which rose to form a zone of stagnant fluid at the top of the container, while the tips of the crystals extended just below the bottom of this light layer. A layer of solid eutectic, with a horizontal front, grew more slowly and filled in the space between the vertically oriented crystals.

The growth of the crystals and the eutectic layer were monitored visually, and in some experiments the temperatures at the top and in the fluid were recorded, until solidification throughout the layer was complete. The solid block was sampled, and the melted products analysed to give vertical concentration profiles. Both the texture and composition are strongly influenced by the fluid conditions during crystal growth. The top concentration is that of the original solution, rapidly quenched against the roof, and the mean concentration through the region influenced by the stable fluid layer is also close to the original. At the bottom the concentration is high, reflecting the in situ growth of close-packed crystals, and there is a sharp decrease in concentration at an intermediate level, between the upper and lower crystal layers.

The experiments and associated theory shed new light on the consolidation of komatiites and the development of their characteristic textures and compositions. Since the lava is convecting within the interior, the early stages of cooling are characterized by a rapid decrease in temperature. Initial cooling rates of 1 to $100^{\circ} \mathrm{C} \mathrm{h}^{-1}$ are calculated. At this stage the crust remains thin, but as the spinifex zone develops, convection progressively decreases in vigour and the cooling rate decreases. Spinifex texture is considered to form by constitutional supercooling which is controlled by compositional convection. As the spinifex texture develops, the olivine dendrites form a layer of depleted fluid. The tips of the crystals extend beyond this differentiated layer into a convecting lower region and grow preferentially to produce the characteristic vertically oriented spinifex texture. The composition of spinifex zones is shown to be close, but not identical, to the initial liquid composition. The compositional profiles of the solid products of the experiments are similar to those found in komatiites, with the most evolved
\end{abstract}


rock compositions being found just above the cumulate zone. The experiments also suggest an alternative explanation to crystal settling for the cumulate zone, in which growth of the spinifex zone by compositional convection concentrates crystals suspended within the turbulently convecting lower layer.

\section{INTRODUCTION}

The basic features of komatiite flows have been described in a number of publications (Pyke et al., 1973; Arndt et al., 1977; Viljoen et al., 1983) and are well summarized in the recent book on komatiites (Arndt \& Nesbit, 1982). The detailed study of spinifex-textured komatiite lava flows in Munro Township by Pyke et al. (1973) and Arndt et al. (1977) has provided a generalized pattern of textural and compositional variations which are apparently common throughout the world (Donaldson, 1982). They divided a typical unit into a lower peridotitic zone characterized by a high proportion of well-shaped equant crystals and an upper zone characterized by spinifex-textured rock in which the crystals have dendritic or skeletal morphologies. These spinifex-textured rocks could often be subdivided into an upper region of randomly oriented crystals and a lower, generally much thicker, region of plate-like crystals, oriented dominantly perpendicular to the flow surface. A thin zone of foliated elongate olivine crystals occurs between the peridotite and spinifex zones.

In komatiites the phenocrysts are entirely olivine whereas in basaltic komatiites clinopyroxene can join or replace olivine as the phenocryst phase. In most cases, except in very thick flows or sills, the groundmass is fine-grained and is inferred to have been originally glassy or quench-textured. Like most generalizations in geology there are many variations and exceptions to this layering scheme. For example, some flows lack spinifex-texture and show no sign of olivine settling, whereas others are entirely composed of randomly-oriented spinifex (Donaldson, 1982). The relative thicknesses of random spinifex, oriented spinifex and the cumulate zone vary greatly from one flow to another even in a single locality.

Variations in mineral and whole rock compositions through layered flows are only known in detail from the Munro Township flows studied by Arndt et al. (1977). More recent studies (Viljoen et al., 1983; Barnes et al., 1984; Arndt, 1986) suggest that these observations can be regarded as general features of layered komatiites. They observed that olivine content and whole rock $\mathrm{MgO}$ content increased upwards in the peridotite zone, reaching a maximum at the boundary with the spinifex rock. They also observed that olivine tended to be more Fe-rich in the spinifex-textured zone. In addition, the spinifex olivines showed a gradation in composition and became increasingly Fe-rich towards the bottom of the zone. Incompatible element concentrations also increased to a maximum at the contact between the two zones (Bickle, 1982).

Many of the variations in both texture and composition have been attributed to rapid cooling of high temperature and low viscosity ultramafic magma, which enables skeletal and dendritic crystal morphologies to form and crystals to settle rapidly to the base of the lava. Other features such as foliation of olivine crystals, internal disconformities and lateral variations have been attributed to continuing flow of lava up to a late stage in the solidification process (Arndt et al., 1977; Barnes et al., 1984).

Komatiites are thought to have been emplaced on the sea floor, where cooling would be dominated by heat transfer to the sea water above, with a smaller rate of heat transfer by conduction into underlying rocks. Part I (Huppert \& Sparks, 1985) considered the process of cooling and crystallization in an actively flowing komatiite lava. The present paper investigates the processes of cooling and crystallization in komatiite lavas after they come to rest. We consider the influence that convective motions, arising from cooling and crystallization within the magma after emplacement, might have on the development of the 
characteristic textures and compositional layering of komatiites. A summary of both investigations appears in Huppert et al. (1984).

Section 2 of the paper describes some results of laboratory experiments using various aqueous solutions, and further details are given in Appendices A and B. The experiments have investigated the effects of roof cooling on the crystallization and convective motions in a lava. In several cases roof cooling has been combined with bottom cooling. The experiments show that compositional convection and the large difference in composition between the original liquid and the solidifying komatiite are important factors in forming spinifex texture. Section 3 presents theoretical calculations to describe some aspects of the cooling and convection process. The calculations are based on a detailed theoretical analysis presented in Appendix $C$. The settling of olivine crystals in a thermally convecting fluid is also analysed. Section 4 considers the implications of these studies for komatiite layering, differentiation and textural characteristics. The investigation supports some of the ideas previously proposed on petrological and geochemical grounds, but also introduces some new concepts.

\section{LABORATORY MODELS OF CRYSTALLIZING MAGMAS}

Experiments were carried out using aqueous solutions to investigate the dynamical features of the convective flows which result from cooling and crystallization. They were designed to model crystallization in komatiite lavas and therefore involved a geometry in which cooling was through the top boundary of the laboratory tank. Chen \& Turner (1980) have already described top-cooling experiments which exhibited some of the features which will be examined in more detail in the present paper.

The growth of crystals in many saturated aqueous solutions (including $\mathrm{KNO}_{3}, \mathrm{Na}_{2} \mathrm{SO}_{4}$ and $\mathrm{Na}_{2} \mathrm{CO}_{3}$ ) leave behind residual fluid which is less dense, though cooler than the original fluid. This is the critical property required to model the decrease in density that occurs in komatiite melts during crystallization of olivine. Chen \& Turner (1980) showed that pools of low density liquid collect at the top of the container when crystallization occurred at the top boundary.

Before describing the experiments designed to model crystallization in a komatiite lava, we outline the philosophy behind such laboratory experiments and summarize some previous results obtained using crystallizing aqueous solutions. The experiments aim to model one or more overall dynamical features of the convective flows which result from cooling and crystallization. Chen \& Turner (1980) used stratified $\mathrm{Na}_{2} \mathrm{CO}_{3}$ solutions to show how layers might form due to double-diffusive convection in compositionally and thermally inhomogeneous magma chambers. They added crystallization to earlier experiments (which had been carried out in an oceanographic context) and demonstrated how the growth of crystals formed by cooling at the top, bottom or side boundaries of a laboratory tank can be influenced by these pre-existing fluid layers. Their top-cooling experiments already exhibited some of the features which will be examined in more detail in the present paper, and reference should be made to their paper for details of the $\mathrm{Na}_{2} \mathrm{CO}_{3}-\mathrm{H}_{2} \mathrm{O}$ system used, and the preliminary results obtained (see their figs. 1, 2,6 and 8 in particular).

All experiments reported below are 'one-dimensional' in character; that is, while the laboratory tank is limited in horizontal dimensions, it can be regarded as a representative section of a much larger region in which the physical and dynamical processes do not vary significantly in the horizontal. Crystallization occurs from the top down and the bottom up in a manner which does not depend on large-scale horizontal variations or flows; any convective motions are purely local (though they can have important horizontal components). 
TABLE 1

Eutectic compositions and temperatures for the aqueous solutions used in these experiments

\begin{tabular}{llcc}
\hline Solute & \multicolumn{1}{c}{ Solid phase } & $\begin{array}{c}\text { Eutectic } \\
\text { composition } \\
\text { (wt. per cent) }\end{array}$ & $\begin{array}{c}\text { Eutectic } \\
\text { temperature } \\
\left({ }^{\circ} \mathrm{C}\right)\end{array}$ \\
\hline $\mathrm{Na}_{2} \mathrm{CO}_{3}$ & $\mathrm{Na}_{2} \mathrm{CO}_{3} \cdot 10 \mathrm{H}_{2} \mathrm{O}$ & $5 \cdot 93$ & $-2 \cdot 1$ \\
$\mathrm{KNO}_{3}$ & $\mathrm{KNO}_{3}$ & $11 \cdot 4$ & $-3 \cdot 1$ \\
$\mathrm{Na}_{2} \mathrm{SO}_{4}$ & $\mathrm{Na}_{2} \mathrm{SO}_{4} \cdot 10 \mathrm{H}_{2} \mathrm{O}$ & $4 \cdot 46$ & $-1 \cdot 3$ \\
\hline
\end{tabular}

Thus, as stated earlier, we are modelling the stage when the flow from the vent has stopped, and the lava is ponded with no overall mean horizontal motion.

We will make specific reference to the crystal morphologies observed in the laboratory and compare these with those seen in komatiite lavas. This extension is justified, we argue, because in both cases the manner in which the crystals grow is determined by very general properties of the fluid environment - whether it is density-stratified or convecting - and the sense of the compositional and temperature gradients. The behaviour of different solutes and combinations of solutes in aqueous solution has been compared and the results are reported in Appendix A. The overall effects were not unduly sensitive to the solute used. The three systems used in most of the experiments all have simple phase diagrams with eutectic parameters shown in Table 1. We also have analysed the solid products of the experiments and found that marked chemical differentiation had occurred which can be usefully compared with the differentiation in komatiites.

\subsection{Experimental techniques}

The experiments were carried out in a cubical Perspex tank measuring $200 \mathrm{~mm}$ on each side internally, which was insulated with a $90 \mathrm{~mm}$ thick polystyrene jacket (removable at front and back for observation). Both the top and the base of the tank (which were kept horizontal) were fitted with metal cooling units, through which alcohol could be circulated to provide controlled temperatures at these boundaries (see Fig. 1). There was a hole at the centre of the top for filling and insertion of thermistor probes, and the top was slightly domed upwards to prevent air being trapped during filling. In some runs a thin sheet of insulating plastic was inserted between the inner and outer portions of the roof unit; temperature measurements made with thermistors embedded in the metal block on each side of this sheet allowed us to estimate the conductive heat flux through the top.

In all the experiments the fluid was initially uniform in temperature and composition. Since the fluid was then cooled below the eutectic temperature for many hours, generally until the whole experimental region became solid, provision had to be made for expansion due to the formation of ice. In early runs, this was done by bleeding off fluid through small holes in the side of the tank from a level which had not yet solidified (and this technique also gave a sensitive direct measure of the amount of eutectic formed). Later, a sliding base, made water-tight with an O-ring seal and supported below on stiff springs to take the weight of the fluid initially, was used both to enable us to vary the depth of the experimental region and to relieve the pressure during solidification. When the tank was filled after the metal top had been precooled to low temperatures, it was found desirable to introduce a final amount of fluid through a hole near the top of one of the side Perspex walls, since premature contact with the cold metal top could produce freezing and blockage round the central hole. 


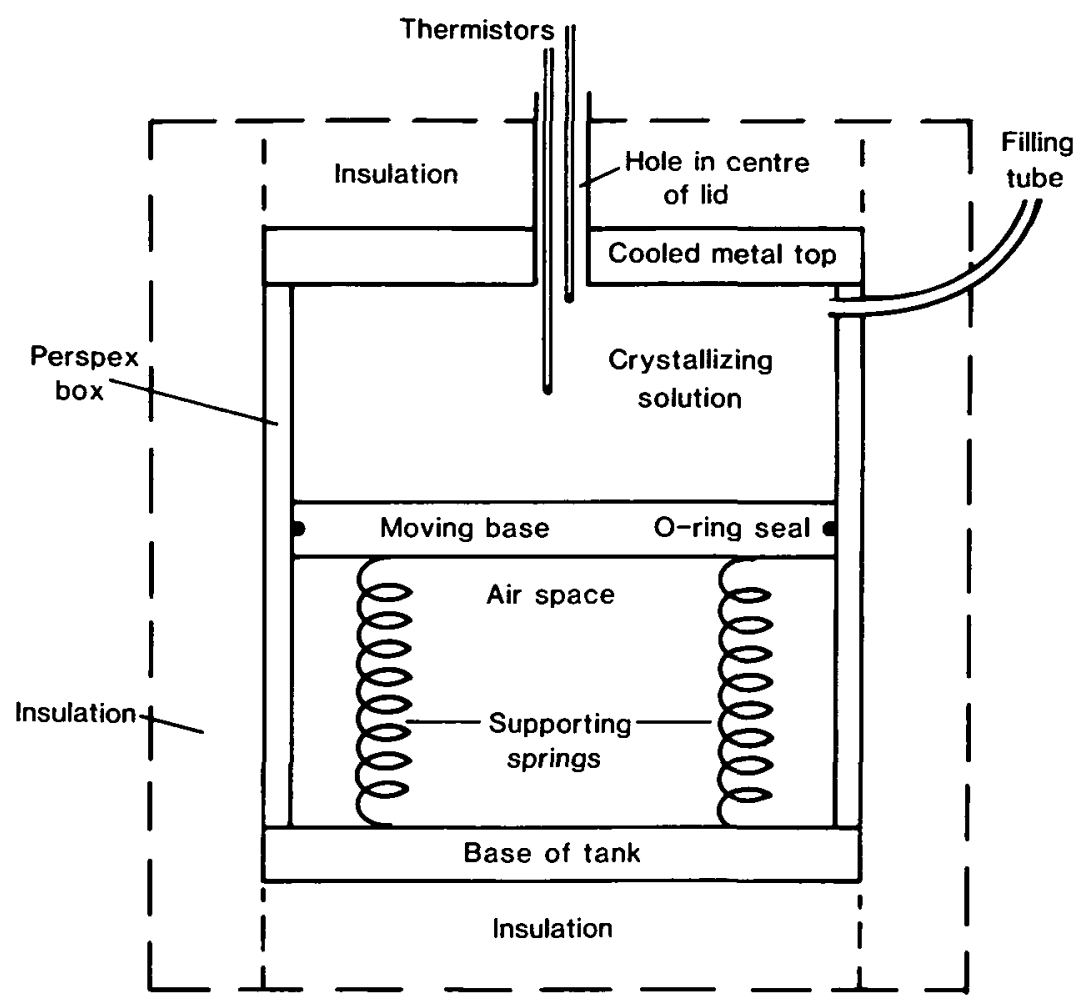

FIG. 1. Sketch of the experimental tank, showing the cooled top, the method of filling, and the sliding base designed to compensate for expansion during freezing.

We recorded visually the progress of the crystallization at frequent intervals, and in a few runs photographed the advance of the crystal front. At the end of the experiment, when the layer of fluid had completely solidified (usually the next day), the tank was dismantled, and the block of crystals plus solid eutectic removed. This was then sampled and analysed using the technique described by Turner \& Gustafson (1981). For a single solute the analysis was most rapidly done using a hand-held refractometer, but chemical methods were required for the multi-component systems. The remaining parts of the solid block were preserved, and the ice allowed to melt and run out of them in a covered container. The structure of the resulting crystalline mass, combined with the concentration measurements, allows us to infer a great deal about the mechanism of formation to supplement the direct observations.

\subsection{Experimental observations}

2.2.1. The development of crystallization due to cooling $\mathrm{Na}_{2} \mathrm{CO}_{3}$ solution at the top

We first describe in detail one experiment which displayed most of the features we wish to document and which were common to most runs. (See Table 2 for a summary of the experimental conditions.) Other runs are described more briefly in Appendix A to illuminate particular points.

This experiment (run A) was carried out using an aqueous solution containing $12.3 \mathrm{wt}$. per cent anhydrous $\mathrm{Na}_{2} \mathrm{CO}_{3}$. At the initial temperature of $31{ }^{\circ} \mathrm{C}$ its S.G. was $1 \cdot 126$. The tank, with the false floor positioned $99 \mathrm{~mm}$ below the roof, was filled with the solution, and then 
TABLE 2

Summary of the laboratory experiments performed

\begin{tabular}{|c|c|c|c|c|}
\hline Solute & Experiment & $\begin{array}{l}\text { Related } \\
\text { figures }\end{array}$ & $\begin{array}{l}\text { Concentration } \\
\text { wt. per cent }\end{array}$ & Remarks \\
\hline \multirow[t]{6}{*}{$\mathrm{Na}_{2} \mathrm{CO}_{3}$} & A & $3,4,5,6$ & $12 \cdot 3$ & $\begin{array}{l}\text { Spinifex texture observed at top with } \\
\text { solid crystals at bottom }\end{array}$ \\
\hline & $\mathrm{C}$ & A2 & 14.8 & $\begin{array}{l}\text { Increased concentration resulted in a } \\
\text { very stable upper layer }\end{array}$ \\
\hline & D & $\mathrm{A} 2, \mathrm{~A} 3$ & $16 \cdot 4$ & $\begin{array}{l}\text { Imposed upper boundary condition } \\
\text { resulted in crystals falling from top in } \\
\text { early stages }\end{array}$ \\
\hline & $\mathrm{E}$ & A2 & $9 \cdot 5$ & $\begin{array}{l}\text { Convection from top was dominated } \\
\text { by cooling }\end{array}$ \\
\hline & G & $\begin{array}{l}11,12 \\
\mathrm{~B} 1, \mathrm{~B} 2\end{array}$ & 5.93 & Eutectic composition \\
\hline & $\mathrm{L}$ & & $\begin{array}{c}17 \cdot 2 \\
+ \text { trace } \mathrm{K}_{2} \mathrm{CO}_{3}\end{array}$ & \\
\hline \multirow[t]{2}{*}{$\mathrm{KNO}_{3}$} & $\mathrm{O}$ & A4, A 5 & 25.5 & $\begin{array}{l}\text { Crystals were held by grid at roof and } \\
\text { a dye layer was trapped at mid depth }\end{array}$ \\
\hline & $\mathbf{J}$ & & 28.0 & No grid at roof, and hence falling crystal \\
\hline \multirow[t]{3}{*}{$\mathrm{Na}_{2} \mathrm{SO}_{4}$} & $\mathrm{~F}$ & & $25 \cdot 5$ & $\begin{array}{l}\text { Eutectic formed immediately with } \\
\text { crystals below it }\end{array}$ \\
\hline & $\mathrm{H}$ & $\mathrm{A} 6, \mathrm{~A} 7$ & $22 \cdot 0$ & $\begin{array}{l}\text { Crystals missing at centre of roof and } \\
\text { only eutectic formed }\end{array}$ \\
\hline & K & $7,9,10$ & $22 \cdot 1$ & $\begin{array}{l}\text { Horizontally uniform crystallization } \\
\text { resulted. Temperature records are } \\
\text { shown in Fig. } 12\end{array}$ \\
\hline 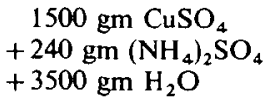 & B & & & $\begin{array}{l}\text { Compositional convection occurred at } \\
\text { both top and bottom }\end{array}$ \\
\hline
\end{tabular}

The experiments taken together show that whatever the crystallizing substance, large density gradients are produced with spinifex texture at the top, more solid crystals at the bottom and a concentration minimum at some intermediate depth.

the alcohol coolant (pre-cooled to $-30{ }^{\circ} \mathrm{C}$ in a large $\approx 501$ external bath) was pumped through the channels in the upper plate. The heat transfer to the coolant caused its temperature to rise, at first rapidly and then more slowly, so that it achieved a steady-state temperature of $-21^{\circ} \mathrm{C}$ after about $45 \mathrm{~min}$.

Strong thermal convection was immediately observed throughout the depth of the fluid. Ice, and some crystals of $\mathrm{Na}_{2} \mathrm{CO}_{3} \cdot 10 \mathrm{H}_{2} \mathrm{O}$ extending below it, began to form at the top after $10 \mathrm{~min}$, and by $15 \mathrm{~min}$, when the temperature of the fluid had fallen to $11^{\circ} \mathrm{C}, 2 / 3$ of the roof was covered, and some crystals of $\mathrm{Na}_{2} \mathrm{CO}_{3} \cdot 10 \mathrm{H}_{2} \mathrm{O}$ were also dropping to the floor. At $17 \mathrm{~min}$, all the top except the central hole was covered by crystals. More crystals continued to fall to the bottom until $25 \mathrm{~min}$ after the start of cooling; at this time the top opening also froze over completely.

The top and bottom crystals grew very differently, and it is the interpretation of this contrast which we believe is of central importance in the application to komatiites. The advancing front of $\mathrm{Na}_{2} \mathrm{CO}_{3} \cdot 10 \mathrm{H}_{2} \mathrm{O}$ crystals at the top consisted of dendrites, which in the early stages grew with the long axes at a wide range of angles to the horizontal. However, as the experiment proceeded, the crystals tended to grow almost vertically downward, perpendicular to the cooled roof. The residual fluid released during crystallization was less dense than the solution from which it formed, and hence ponded at the top of the tank. It thereby formed an almost static, cold stable layer with a density front below it. The tips of the 


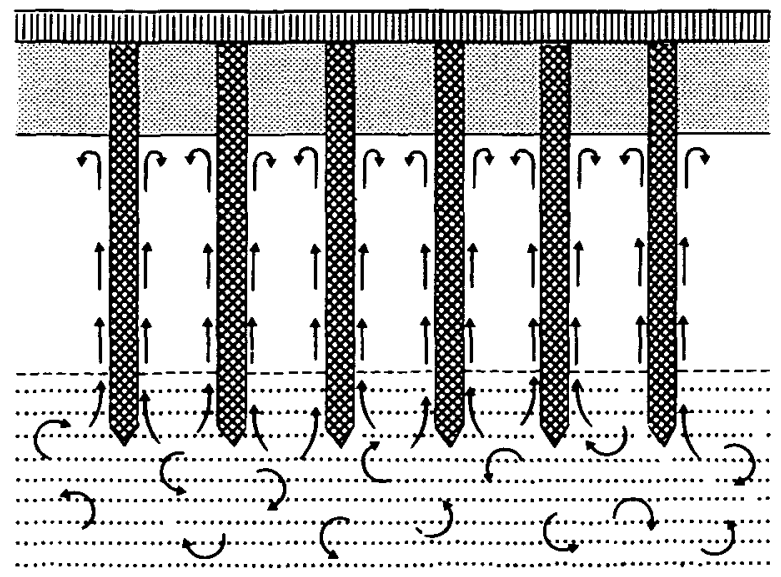

\title{
QUENCH LAYER
}

SOLID EUTECTIC LAYER

\author{
STATIC STRATIFIED
}

SOLUTE-POOR LAYER

\section{CONVECTING}

SOLUTE-RICH LAYER

FIG. 2. A schematic sketch of: the growth of the predominantly vertical dendrites; the compositional convection; and the different layers set up, when an aqueous solution is cooled strongly from above. The tips of the dendrites extend into the convecting lower layer where further crystallization releases light liquid which rises along the dendrite faces to form a compositionally stable layer. Below the quench layer, formed on the initial cooling, a solid eutectic layer expands into the spaces between the dendrites.

dendrites always extended slightly beyond this front into the convecting solute-rich fluid below. The only motions in this non-convecting layer were those due to local upflow along the crystals caused by compositional convection. A schematic diagram summarizing the fluid and solid layers which formed and the fluid motions observed within them is shown in Fig. 2.

We interpret the predominantly vertical downward growth of these dendrites as being due to the fact that the concentration was higher just below the interface, while cooling by conduction extended through the interface and produced supersaturated conditions at the tips of the growing crystals. The mechanism is like constitutional supercooling on a large scale, except that the temperature and compositional gradients are formed by both diffusion and convection. The general level of the crystal fronts was nearly horizontal, constrained by the interface bounding the upper stable region, which was gravitationally controlled. Particularly at later stages as the temperature fell (and because the composition remained constant the supersaturation must have increased), some crystals grew more rapidly and extended through and below the interface. A sequence of photographs is shown in Fig. 3 .

A second feature of the crystallization at the roof is also shown in Figs 2 and 3 . Since the roof temperature was much lower than the eutectic temperature $\left(-2 \cdot 1{ }^{\circ} \mathrm{C}\right)$, a eutectic layer formed between the dendrites, and grew downwards with a horizontal front below. Its growth rate was less than that of the dendrites, but for the first hour roughly proportional to it (see Fig. 4). It is shown in Appendix A below that the ratio of these growth rates depends systematically on the initial concentration of the solution. The ratio of the growth rate decreases as the composition of the solution approaches the eutectic. Figure 4 also shows that following the initial period of relatively steady growth, the dendritic crystals grew faster and more irregularly for a time, while the rate of advance of the eutectic layer gradually decreased. After about $2 \mathrm{~h}$, the rate of advance of the tips of the crystals became much slower, but the crystals were observed to continue to thicken and grow sideways.

We now consider the concurrent growth of crystals from the bottom. The initial crystals fell to the floor with an orientation which was largely horizontal because of their flat, elongate habit, but which was otherwise random. They then remained relatively passive until 

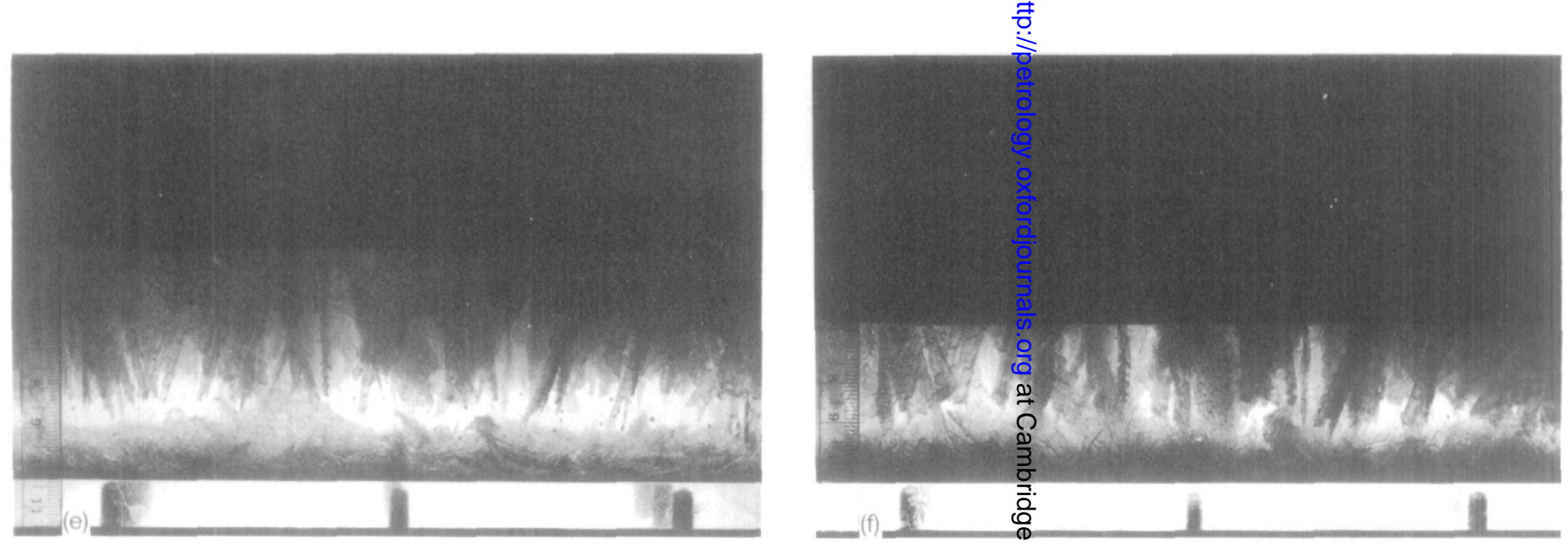

FIG. 3. (e) 5 h $58 \mathrm{~min}$ (f) $10 \mathrm{~h} 6 \mathrm{~min}$.

产.
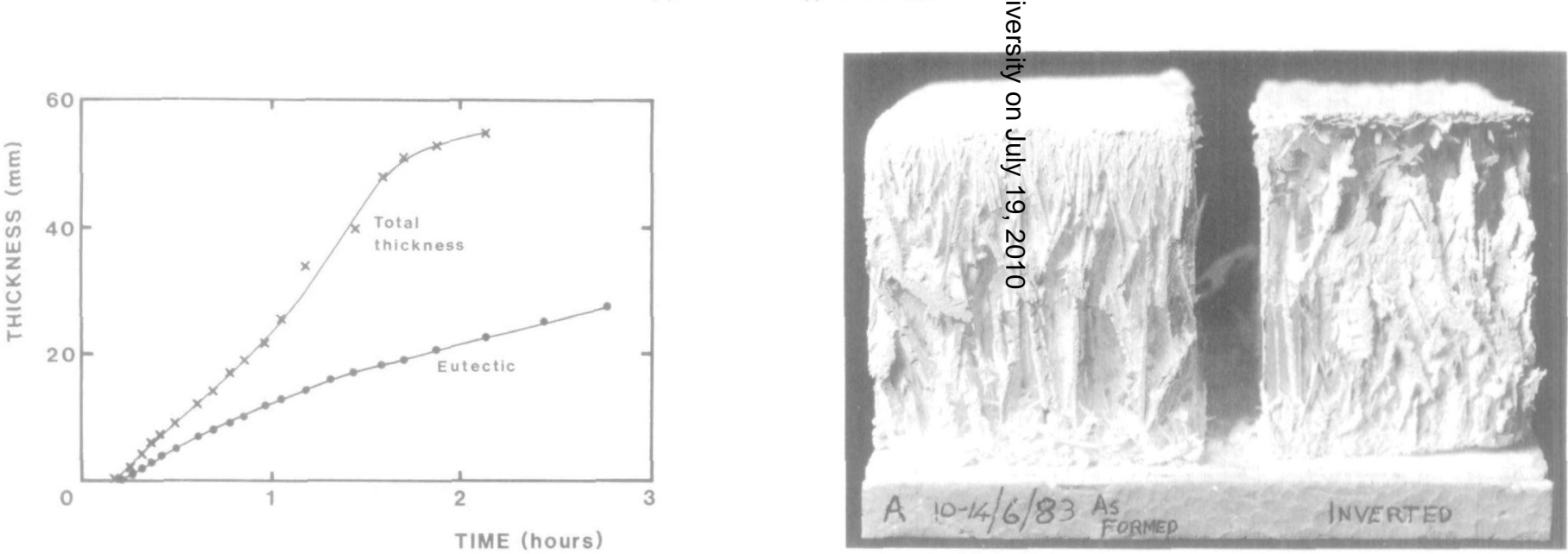

FIG. 4. The total thickness of the crystals at the roof, and that of the eutectic layer embedded in it, as a function of time for the early part of run $\mathrm{A}$.

FIG. 5. The crystal block formed in run A. The ice was allowed to melt and run out of the upright and inverted halves of the block, and partial dehydration had occurred by the time the photograph was taken. 


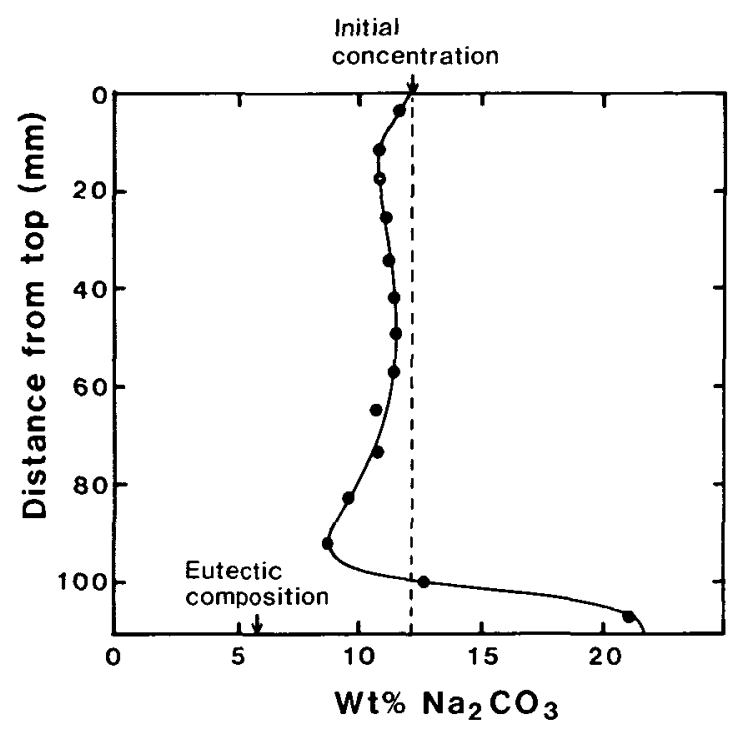

FiG. 6. The concentration profile in run A, measured by cutting horizontal strips from a central slice after the block was completely solid. The strips were allowed to melt, and diluted appropriately when necessary. The refractive index was the property actually measured.

about $40 \mathrm{~min}$, when they acted as nuclei for in situ growth. Strong compositional convection occurred above them as light residual fluid was released, and this contributed to the convective stirring of the lower layer but did not penetrate through into the upper stratified region. The crystals continued to grow in the flat-lying position, but later some further dendritic crystals nucleated and began to grow upwards, as can be seen in Fig. 3. The upper and lower crystals approached one another and eventually overlapped to some extent, but a thin fluid layer, where the volume density of crystals (as judged visually) were clearly a minimum, persisted until the eutectic layer moved through it and solidification was complete. The final thickness of the solid layer was $109 \mathrm{~mm}$, an increase of $10 \mathrm{~mm}$ or 10 per cent due to the formation of ice. The thickness of the layer of crystals on the bottom, and thus the position of the final crystal-depleted layer, will be shown later to vary systematically with the initial concentration. This thickness also depends on the rate of cooling. It is greater when crystals can fall from the roof before the eutectic temperature is reached, rather than being held there immediately by an ice layer.

The features of crystal growth described above are illustrated by Fig. 5, which shows photographs of the crystal mass after the ice had melted and the $\mathrm{Na}_{2} \mathrm{CO}_{3} \cdot 10 \mathrm{H}_{2} \mathrm{O}$ crystals had partly dehydrated. One part of the block was inverted before melting took place. On the left, from the top down, we see the dense mass of fine crystals against the roof; the thin vertically oriented dendritic crystals below this; a gradual thickening to a plate-like form in the centre of the block, but still with a predominantly vertical orientation; the gap where the concentration of crystals is low; and finally, at the floor, the dense layer of crystals with axes more nearly horizontal.

The vertical concentration profile in the solid block, measured using a refractometer by the technique described previously, is shown in Fig. 6. There is good internal consistency, and we consider this is an accurate measure of the horizontally averaged concentration as a function of depth. The top concentration is just that of the original solution, rapidly quenched against the cold roof (see Fig. 2). The concentration decreases for a short distance 
below this, as the non-convecting layer under the roof is depleted of solute by crystals falling to the bottom, so that a larger fraction of eutectic is formed, and then it increases again with increasing depth, reflecting the in situ thickening of $\mathrm{Na}_{2} \mathrm{CO}_{3} \cdot 10 \mathrm{H}_{2} \mathrm{O}$ crystals before they were overtaken by the eutectic layer. At the bottom there is a high concentration due to the close-packed crystals which fell there and then grew, with a sharp decrease above this to a minimum, much less than the original concentration, at a height corresponding to the gap observed visually. In a similar experiment using $\mathrm{KNO}_{3}$, described in detail in Appendix A2, red dye was added to the convecting layer. The dye acted as an incompatible trace constituent and was concentrated at the level of lowest concentration of the main solute in the solid block, forming a thin red band. The experiment illustrated how incompatible elements become highly concentrated at the level which solidifies last.

\subsubsection{Experiments using $\mathrm{Na}_{2} \mathrm{SO}_{4}$ : temperature measurements}

In several runs using $\mathrm{Na}_{2} \mathrm{SO}_{4}$ solution, temperatures were measured as a function of time at two depths in the crystallizing solution. It is instructive to relate the temperature records to the visual observations of the growth of the crystals. During the experiment to be described first (run K) a time lapse film was also made, allowing us to monitor the experiment over $14 \mathrm{~h}$. The original solution for run $\mathrm{K}$ was 22.1 wt. per cent $\mathrm{Na}_{2} \mathrm{SO}_{4}$, of S.G. 1.208 at $31^{\circ} \mathrm{C}$, which is approximately the temperature at which the $80 \mathrm{~mm}$ deep layer of fluid was poured into the tank. The coolant was at $-28{ }^{\circ} \mathrm{C}$, and the pumping through the roof to pre-cool it was started at the same time as the inflow. After 12 min the solution touched the roof and immediately crystallized, first round the edges (at the lowest point), and then extending in toward the centre. A particular advantage of $\mathrm{Na}_{2} \mathrm{SO}_{4}$ was that the entire crystal mass was locked in place at this stage, even without the formation of any ice, and all air was forced out through the central hole as the crystals grew in from the sides.

As soon as the roof was completely covered, fine dendritic crystals began to grow down nearly vertically, with a sharp horizontal lower boundary. Their tips extended slightly below a distinct fluid interface. After $33 \mathrm{~min}$, a eutectic layer was observed, extending down below the roof, and at about the same time crystals were observed on the bottom. The further growth of the top and bottom crystals will be described in conjunction with Fig. 7, which is a reproduction of a chart recording of temperatures measured with thermistors placed at 15 and $43 \mathrm{~mm}$ below the roof.

Both thermistors indicated a slight rise in temperature at $A$ as the air in the box was warmed briefly by the inflowing solution, a larger drop (B) when cooling from the roof took effect, and then a rapid rise again (C) as the fluid reached each thermistor in succession. (Note the offset in the time origin for the two sensors.) Cooling at both depths then proceeded at nearly the same rate, with large fluctuations indicating turbulent convection throughout the layer containing the two thermistors. At about $38 \mathrm{~min}(\mathrm{D})$, the fluctuations at the upper thermistor decreased to negligible values because it was in a non-convecting region, and the rate of fall of temperature increased as the tips of the crystals (and the upper stable fluid layer) grew down below the thermistor at $15 \mathrm{~mm}$. After the crystals had grown past the thermistor at $15 \mathrm{~mm}$, the temperature of the upper layer continued to fall and the temperature of the lower (still convecting) layer stayed almost constant (E). This was a consequence of the smaller heat transfer through the interface above the lower layer and the release of heat of crystallization by crystals growing on the bottom. After about $88 \mathrm{~min}$ into the experiment, the rate of bottom crystallization was so great that the temperature actually rose for a while (F), with vigorous superimposed fluctuations, until at $2 \mathrm{~h} 10 \mathrm{~min}$ the interface passed the $43 \mathrm{~mm}$ mark and both thermistors were in the upper stable layer. 


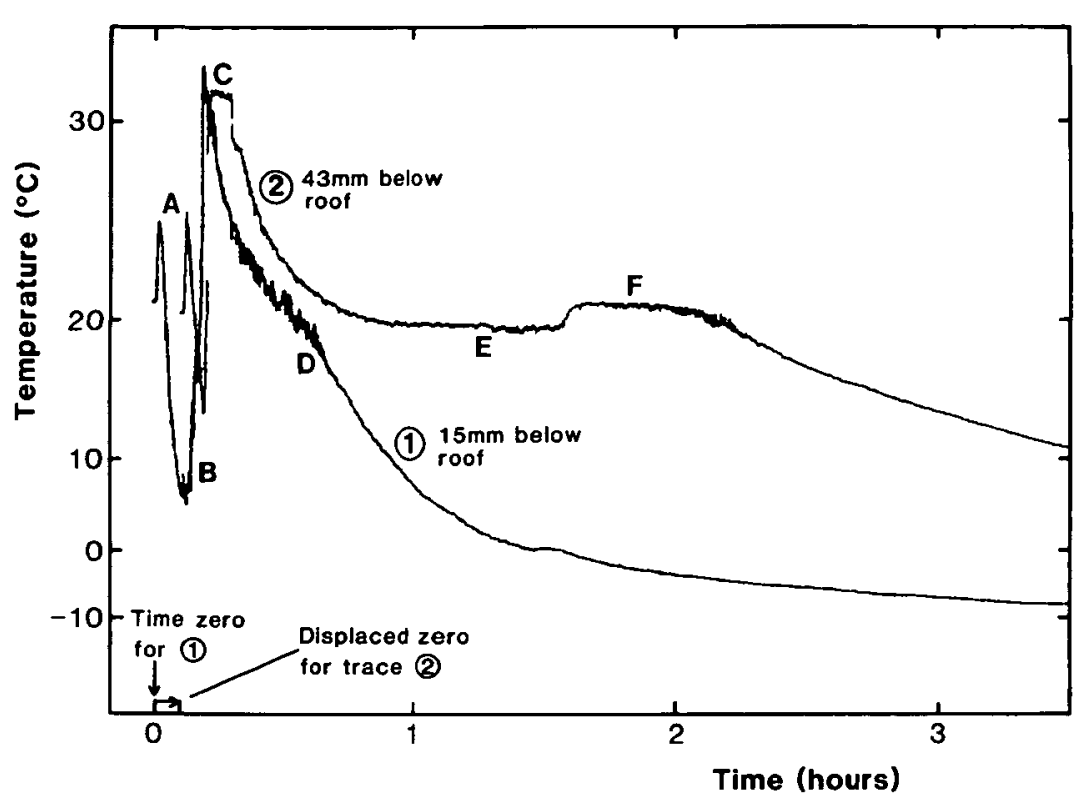

Fig. 7. Reproduction of a chart recording of the temperatures measured by two thermistors at (i) $15 \mathrm{~mm}$ below the roof and (ii) $43 \mathrm{~mm}$ below the roof in a crystallizing $\mathrm{Na}_{2} \mathrm{SO}_{4}$ solution (run $\mathrm{K}$ ). See text for the interpretation of various details.

The extreme difference between the environments in which the crystals were growing at $\frac{0}{\omega}$ the top and the bottom is highlighted by comparing the records at, say, $80 \mathrm{~min}$. The upper layer was stable, with very small temperature fluctuations; and the temperature at $15 \mathrm{~mm}$ depth was $+1{ }^{\circ} \mathrm{C}$. The lower layer was at this time vigorously convecting due to composi- $\vec{\Omega}$ tional as well as thermal effects and its mean temperature was $19^{\circ} \mathrm{C}$. The effects of this convection did not penetrate through the interface. We did not measure temperature as a function of depth in this experiment, but it is instructive to reproduce in Fig. 8 comparable $\frac{0}{\infty}$ measurements reported by Chen \& Turner (1980) for the $\mathrm{Na}_{2} \mathrm{CO}_{3}-\mathrm{H}_{2} \mathrm{O}$ system. Note that the stable density gradient of the upper fluid layer, which was contained in the interstices between nearly vertical dendritic crystals, was dominated by the compositional gradient. This was partly compensated by an opposing destabilizing temperature gradient (with colder fluid at the top), which was not sufficient to cause it to become unstable and convect, or to be supersaturated at any level. It is also relevant to mention that the form of the concentration and temperature profiles in this region is consistent with the idea that the stratification was produced by laminar upflows of cold depleted solution rising along the dendritic crystals, though in the present case there will also be a direct contribution from the cooling at the roof. Worster \& Leitch (1985) have recently obtained a much clearer understanding of the closely

The physical features of the crystals formed in run $\mathrm{K}$ were similar to the results with other solutes. The concentration profile is very clearcut, however, and for this reason it is reproduced in Fig. 9, and a photograph of the same experiment shown in Fig. 10. The composition is practically uniform through the upper $50 \mathrm{~mm}$, there is a sharp decrease to a minimum at $65 \mathrm{~mm}$ (in a region where there is a distinct gap in the crystals after the eutectic has melted and run out), and a maximum at the bottom where the crystals have fallen and grown in a close-packed mass. The low value measured at the bottom point (under the 


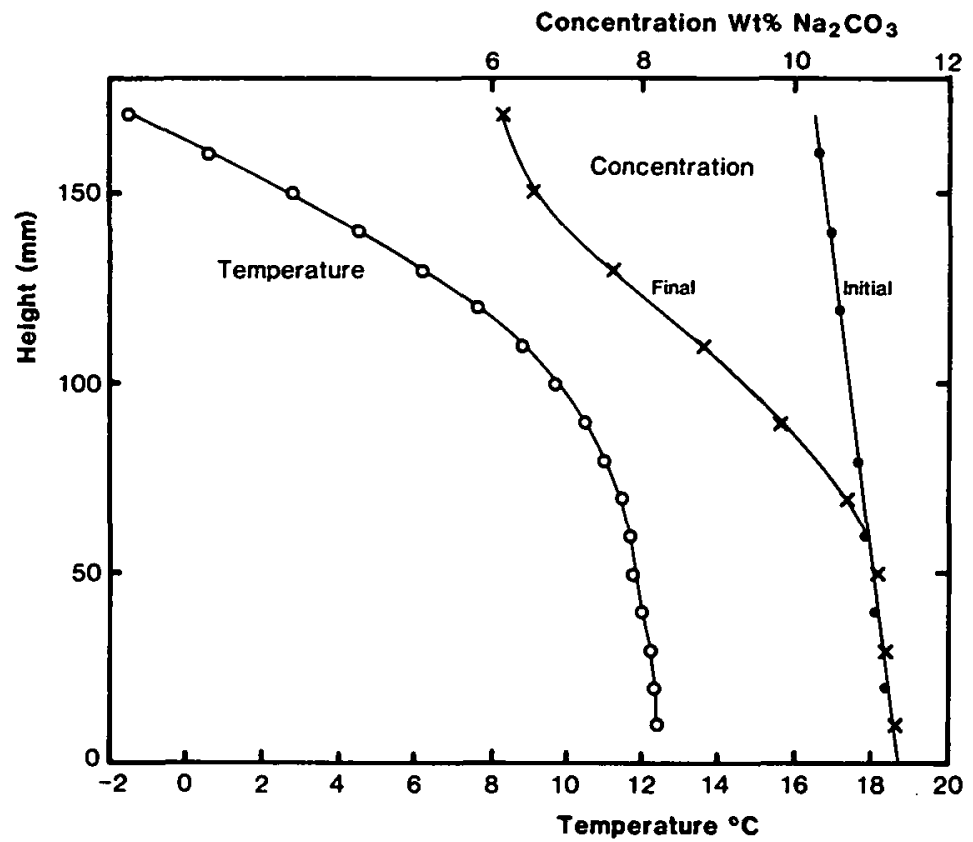

FIG. 8. Reproduction of the data shown in Fig. 8 of Chen \& Turner (1980). These concentration and temperature distributions, developed in a weak gradient of $\mathrm{Na}_{2} \mathrm{CO}_{3}$ solution cooled from above, were measured in the fluid between long dendritic crystals, above which was a thick layer of eutectic.

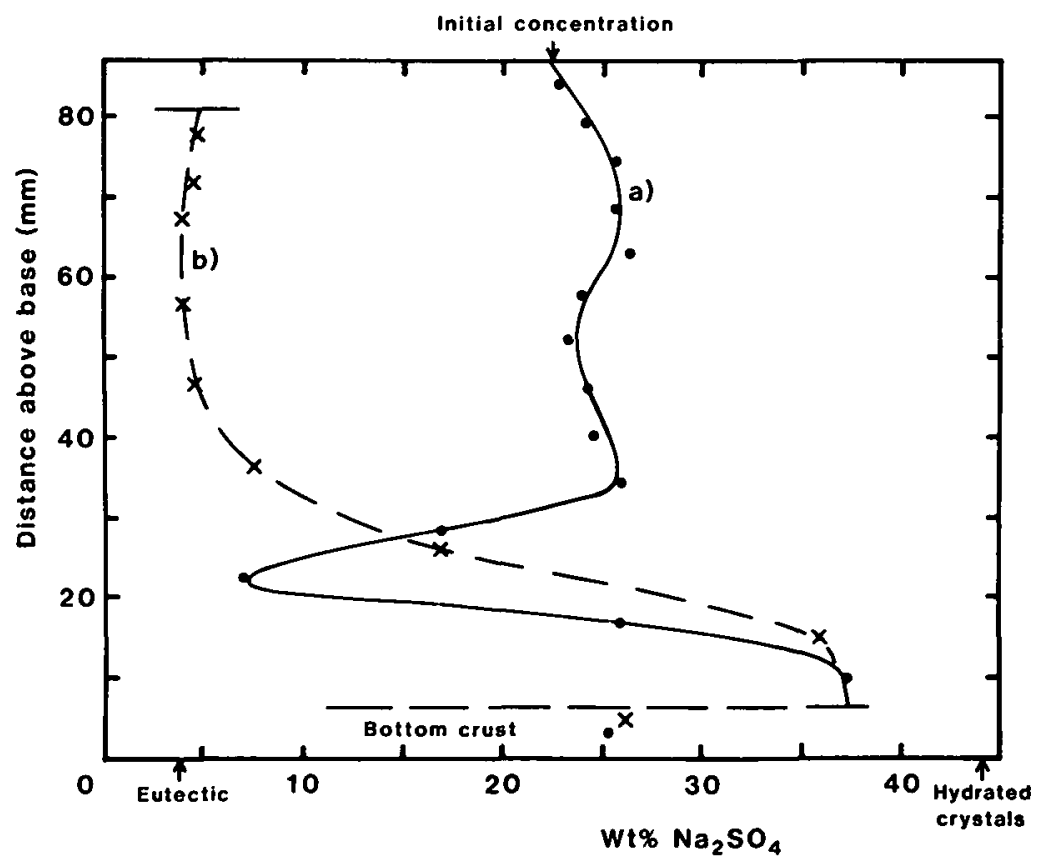

FiG. 9. The concentration profile measured in the solid block following run $\mathrm{K}$, using $\mathrm{Na}_{2} \mathrm{SO}_{4}$ solution. (Compare with Fig. 6.) Note the thin layer of lower concentration at the bottom, formed by eutectic flowing under the solid crystal mass as expansion took place. 


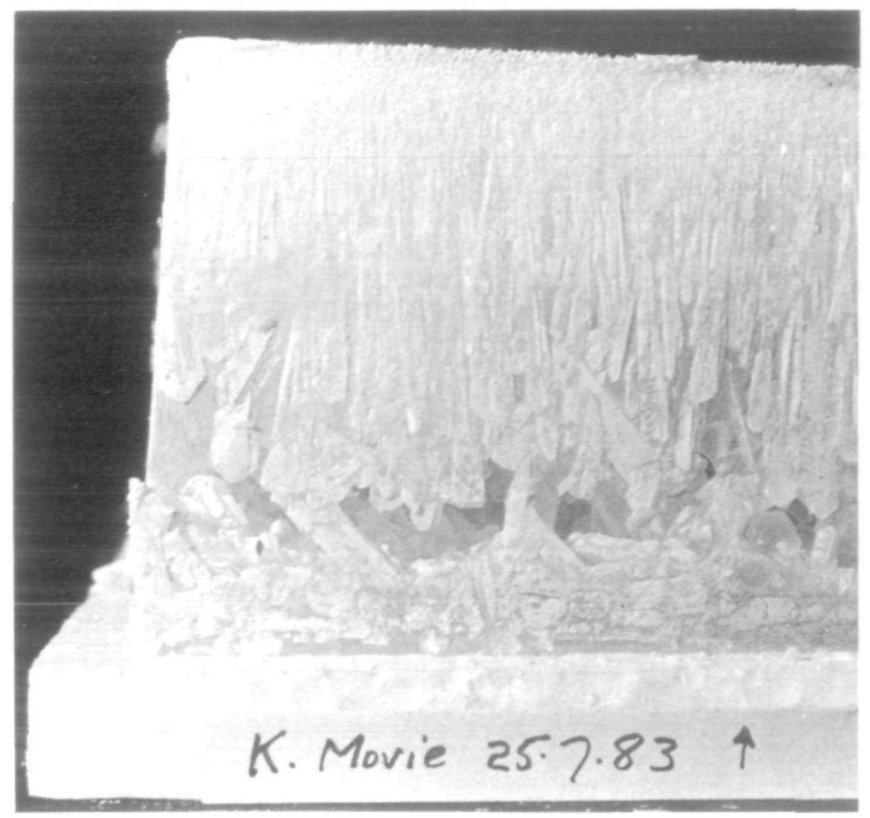

FIG. 10. The crystal block formed in run $\mathrm{K}$, after the eutectic had melted and run out.

dashed line) is due to fluid near the eutectic composition flowing under these crystals, which remained anchored on the side walls at a fixed depth as the false bottom responded to the change in volume. The contrast between the vertical structure of crystals growing from the top, and the random orientation and close packing at the bottom, is very marked in Fig. 10

\subsection{Quantitative study of eutectic growth}

The significant observations discussed so far (as well as those referred to in Appendix A) have been largely qualitative, though we have also reported some measurements of the growth rates of crystals and eutectic, as well as concentration profiles, to support our descriptions of the dynamical evolution of a crystallizing layer cooled strongly from above. Before we can confidently transfer the understanding we have gained to the prototype komatiite flows, we need to go further. We should ideally be able to relate the cooling rate and rate of solidification to the externally imposed conditions (in particular the temperature at the roof), in a way which allows us to test a quantitative theory on laboratory data, and then use this theory to describe the time history of a solidifying lava. As a first step, we have studied in some detail the $\mathrm{Na}_{2} \mathrm{CO}_{3}-\mathrm{H}_{2} \mathrm{O}$ system, using a layer of solution of eutectic composition crystallizing from the top. In this special case, there is only a single, plane horizontal advancing front of eutectic solid, with no dendrites or stable fluid layer below it. This allows the relevant theory to be simpler than for a general, non-eutectic initial
composition and it can be compared with experiments in a straightforward manner. Even though the special case is considerably simplified, we believe that the theory can shed considerable light on the processes and timescales involved in more complicated situations.

We carried out several experiments with $\mathrm{Na}_{2} \mathrm{CO}_{3}$ solution near the eutectic $(5.93 \mathrm{wt}$. per cent $\mathrm{Na}_{2} \mathrm{CO}_{3}$ ), but will describe in detail only the one (run $\mathrm{G}$ ) in which cooling from the top was strongest, and the measurements most nearly complete. We measured, as a function of time, the thickness of the solid eutectic layer, the temperature at mid-depth in the 


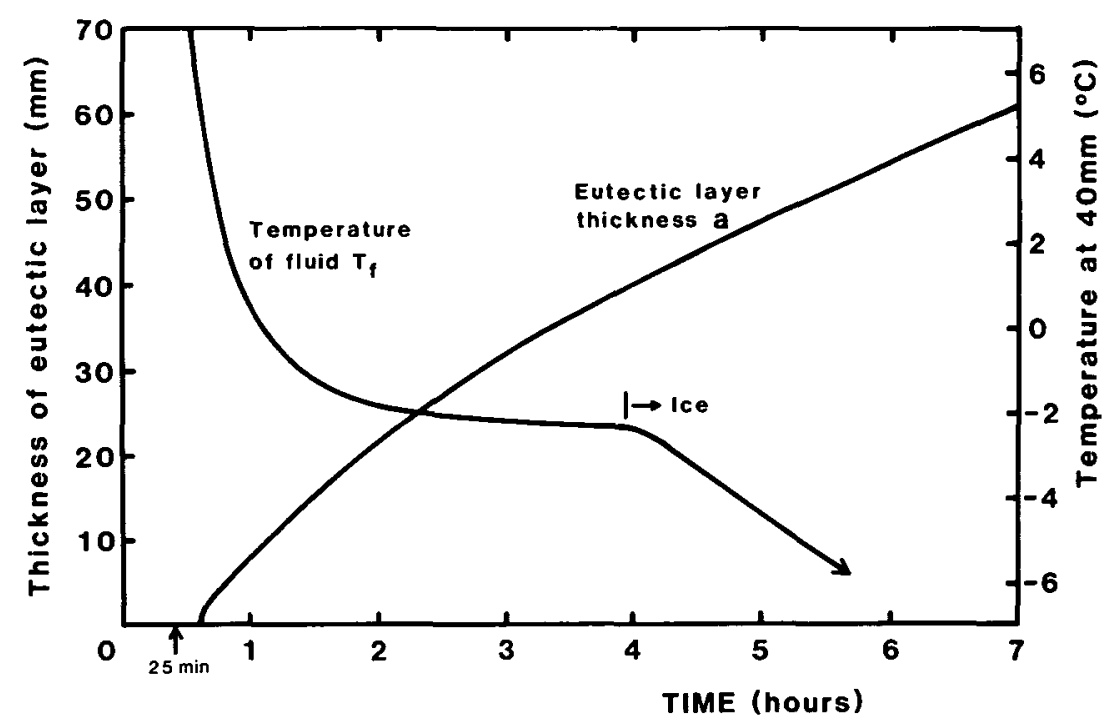

FIG. 11. The growth of the eutectic layer thickness $a$, and the change in temperature of the fluid layer $T_{f}$, for run $\mathrm{G}$, in which a layer of $\mathrm{Na}_{2} \mathrm{CO}_{3}$ of eutectic composition was cooled strongly from the top.

$80 \mathrm{~mm}$ deep layer of solution, the coolant temperature, and, as a measure of the heat flux through the roof, two temperatures at the centre of the top cooling plate, inside and outside a thin insulating sheet. The extent to which the first two (internal) observations can be predicted from one or more of the roof temperature records will be used as a test of the theory which follows.

The data requiring a quantitative explanation are shown in Fig. 11. The time origin is arbitrary: $t=0$ corresponds to the time when coolant at $-31{ }^{\circ} \mathrm{C}$ began circulating through the roof, with the top of the fluid layer $10 \mathrm{~mm}$ below. The effective start of the experiment was at $25 \mathrm{~min}$, when the tank was topped up and solution (at a temperature of $13.5^{\circ} \mathrm{C}$ ) touched the roof. A complete covering of eutectic immediately formed on the roof, but this receded again due to the strong convective transport of heat from the interior to the boundary. The consequent rapid cooling of the fluid (to $5.9{ }^{\circ} \mathrm{C}$ at $35 \mathrm{~min}$ ) allowed the eutectic layer to form again, extending inwards from the corners. By $37 \mathrm{~min}$, the roof was covered with an approximately $2 \mathrm{~mm}$ thick layer. (The final stage of this process took place too rapidly, and the eutectic layer was too thin and non-uniform for reliable measurements to be made. It should be noted that the thickness recorded was measured using a single scale placed along one side of the front of the tank.) From this time on the layer thickened, as shown in Fig. 11, at an almost constant rate until $80 \mathrm{~min}$, and thereafter at a steadily decreasing rate. Note immediately that the time scale for convective cooling of the fluid layer (of order $1 \mathrm{~h}$ ) is much shorter than that for complete solidification $(\approx 12 \mathrm{~h})$. The rapid cooling takes place while the solid eutectic layer is thin, and the temperature gradient and rate of conduction of heat across it is therefore large. (The shorter time-scale is also characteristic of the formation of dendritic crystals, when that is possible in more concentrated solutions. This is of course not immediately relevant for the eutectic experiments, but it is an important feature of the modelling of komatiite solidification, which must continually be kept in mind. It will be discussed in more detail later.) The final temperature measured in the fluid layer (just before $4 \mathrm{~h}$ ) was $-2 \cdot 3{ }^{\circ} \mathrm{C}$, which is close (within the accuracy of our measurements), to the eutectic temperature. The more rapid fall after that time was due to the fact that the thermistor 


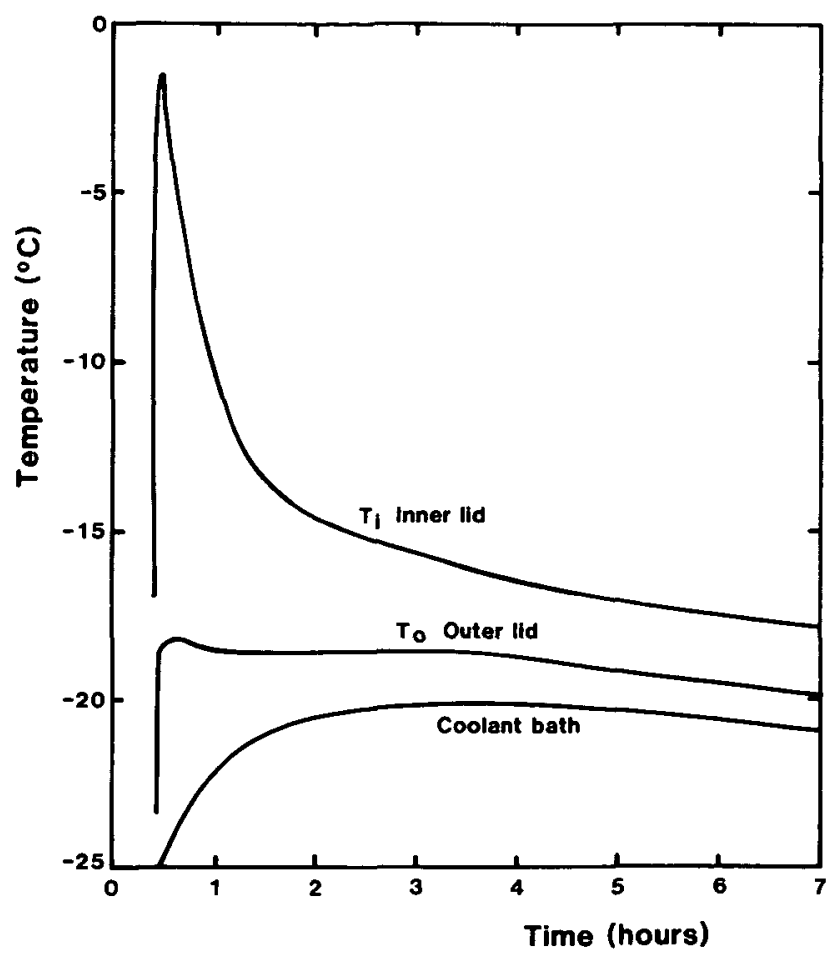

FIG. 12. The three externally imposed temperatures controlling the cooling at the top boundary in run G: The temperature in the 501 bath of coolant; $T_{0}$, the temperature of the outer lid through which coolant is circulated: and $T_{i}$, the temperat ure of the inner lid, which is in contact with the fluid and separated by a thin insulating sheet from the outer lid.

became embedded in the solid eutectic layer, and was a measure of the steep conductive temperature gradient through the solid.

The three temperatures determining the externally imposed conditions at the roof are plotted in Fig. 12. The temperature of the coolant in the bath will not be used explicitly, but it is included for completeness. The outer lid temperature rose rapidly when the fluid reached the roof, but it soon achieved a steady state which was maintained for $3 \mathrm{~h}$, and then the temperature gradually fell again. The temperature of the inner lid rose very sharply as the fluid touched it, then fell again quite rapidly up to $80 \mathrm{~min}$, during the period when the fluid temperature was falling and the eutectic layer was growing at an almost constant rate. Thereafter the rate of change of this temperature decreased markedly, and after $4 \mathrm{~h}$ the temperature difference between the inner and outer lids remained almost constant in time. $\vec{\bullet}$

The large differences and rapid changes in this temperature difference have made it $\tilde{O}$ difficult to estimate the heat flux through the roof (as discussed below). There are however $\overrightarrow{0}$ some immediate consistency checks which can be made on these measurements, without developing the detailed theory, but with some knowledge of the flux balance to be expected at various stages. These are described in Appendix B.

\section{THEORY}

Previous investigations of the cooling of lava flows after emplacement have used ideas based on thermal conduction (Jaeger, 1968). The study of Usselman et al. (1979) on komatiite lavas considered the influence of convection on cooling, and did so by arbitrarily modifying 
the value of the heat transfer coefficient in the conduction model. However, the determination of quantitatively reliable results requires a more explicit treatment of the heat transfer in the convecting fluid. In Appendix $\mathrm{C}$ we develop a quantitative model for the cooling from above of a fluid of eutectic composition which is compared with the experimental results presented. This is a necessary first step towards analysing the more complicated situation where significant crystal growth can take place at the roof as in a komatiite or in other non-eutectic compositions. The analysis demonstrates that when convection is important, both the rate of cooling of the interior of the fluid and the rate of growth of the upper crust are fundamentally different from the values based on thermal conduction models. We provide below a brief synopsis of the results and main consequences for understanding solidification of komatiite lavas.

In a lava flow where cooling occurs predominantly through its roof, three models can be envisaged. In the first case a crust forms and in the interior the fluid lava remains static. The growth rate of the crust and the cooling of the interior are governed by conduction of heat to the exterior. The cooling is calculated by balancing the conductive heat flux through the crust, $F_{\mathrm{C}}$, with the flux due to latent heat release, $F_{\mathrm{L}}$. This is the model previously used to calculate the cooling history of lavas (Jaeger, 1968; Usselman et al., 1979) and is entirely appropriate if neither thermal nor compositional convection occur within the fluid interior. While convection is not likely to occur in most basalt flows, the much lower viscosity of komatiite lava results in convection being important, even in thin flows (see Appendix C).

In the second case a crust forms, but the fluid in the interior is convecting. The simplest system is for a eutectic composition and so the composition remains constant as the crust grows. This is the case analysed quantitatively in Appendix $\mathrm{C}$ and which is compared with our experimental results. The appropriate heat balance is given by:

$$
F_{\mathrm{C}}=F_{\mathrm{L}}+F_{\mathrm{T}}
$$

where $F_{\mathrm{T}}$ is the convective flux from the fluid layer. The fluxes $F_{\mathrm{C}^{\prime}} F_{\mathrm{L}}$ and $F_{\mathrm{T}}$ are defined by equations (C2), (C3) and (C4) in Appendix C. An important result of this theory is that the rate of cooling in the interior of the lava can be orders of magnitude more rapid than in the conductive case. The rate of growth of the crust is also not related to the square root of time as in the familiar conduction model. In contrast the crust remains thin while there is a substantial decrease of the interior lava temperature. A comparison of the conductive and convective models is made in Appendix $\mathrm{C}$ to illustrate the fundamental differences between the models. We emphasize that neither model is in fact directly appropriate for the quantitative analysis of the complete cooling history of a komatiite lava. However, the convective model should give a good idea of conditions in the early stages of cooling, whereas the conductive model is appropriate in the late stages of cooling.

The third case involves the development of a zone of dendritic crystals growing from the roof (the spinifex zone). This is the situation examined in the non-eutectic experiments and is thought to be the pertinent case for komatiites. The interior lava is convecting and a crust of eutectic composition grows between the dendritic crystals. Between the crust and the thermally-convecting interior a mushy zone of dendrites occurs in which there is compositional convection. Unfortunately, a quantitative model of this case has yet to be developed since the analysis is substantially complicated by the spinifex zone and the compositional convection within it. Nevertheless, some qualitative statements can be made on the basis of the theoretical understanding gained in Appendix C. The fact that convection is involved implies that the early stages of cooling will be much more like the simple convective eutectic case than the conductive case.

In particular in the initial stages of cooling of a komatiite when a thin crust has formed and 


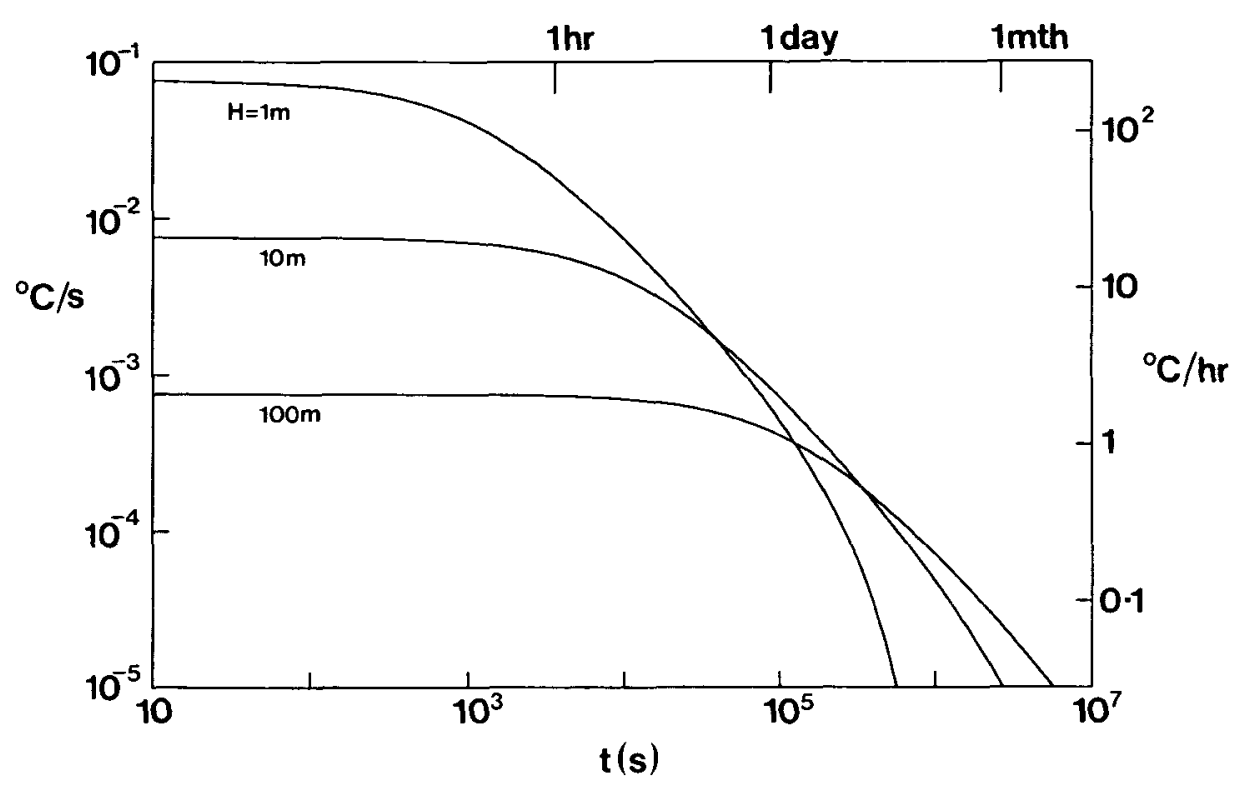

FIG. 13. The cooling rate as a function of time of ponded komatiite lavas cooled from above, of thicknesses 1 , 10 and $100 \mathrm{~m}$.

the main oriented spinifex zone has yet to develop, the cooling rates in the interior of the flow will be large and should be comparable to those predicted in Appendix $\mathrm{C}$ for the eutectic $\frac{\partial}{\omega}$ case. For example, initial cooling rates of $1-100^{\circ} \mathrm{C} \mathrm{h}^{-1}$ can be expected after emplacement $\stackrel{\circ}{\circ}$ of a $1600^{\circ} \mathrm{C}$ flow (Fig. 13). These rates are not quite as large as those calculated for forced $\stackrel{0}{\stackrel{0}{f}}$ convection in Part I (Huppert \& Sparks, 1985), but are still large enough to anticipate that $\vec{\odot}$ skeletal and hopper olivine morphologies could form and that the interior lava could $\stackrel{\varrho}{5}$ become highly supersaturated.

Once the oriented spinifex zone begins to develop, however, the cooling rate and crustal $\frac{0}{0}$ development will increasingly depart from the eutectic model. Qualitatively the effect of the $\subseteq$ growing spinifex zone would be to decrease the cooling rate, although as long as the interior $\underset{\Phi}{\gtrless}$

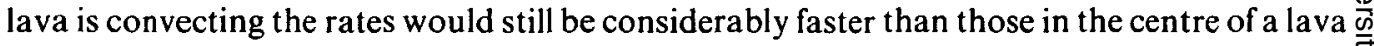
cooling by conduction alone. At some stage when the spinifex zone is thick and the interior lava has increased its viscosity sufficiently to dampen convection, the cooling will be entirely controlled by conduction.

The behaviour of olivine crystals dispersed within the convecting interior of the lava is of $\vec{\omega}$ interest for understanding how the lower B-layer peridotite might originate. An indication of $N$ the likely effects of thermal convection can be assessed from work on the typical fluid $\stackrel{\circ}{\circ}$ velocities attained during thermal convection between two parallel plates (Deardorff \& Willis, 1967). The time-averaged vertical velocities $w_{\mathrm{m}}$ in the centre of the fluid layer are found to be related to the heat flux and other physical parameters for $R a>10^{6}$ by

$$
w_{\mathrm{m}}=B\left[(g \alpha \Delta T)^{4} K_{\mathrm{T}}^{2} d^{3} / \nu\right]^{1 / 9},
$$

where $B$ is a constant with an experimentally determined value of 0.44 . The Stokes free-fall velocity is given by

$$
V=2 \Delta \rho g l^{2} / 9 \mu,
$$




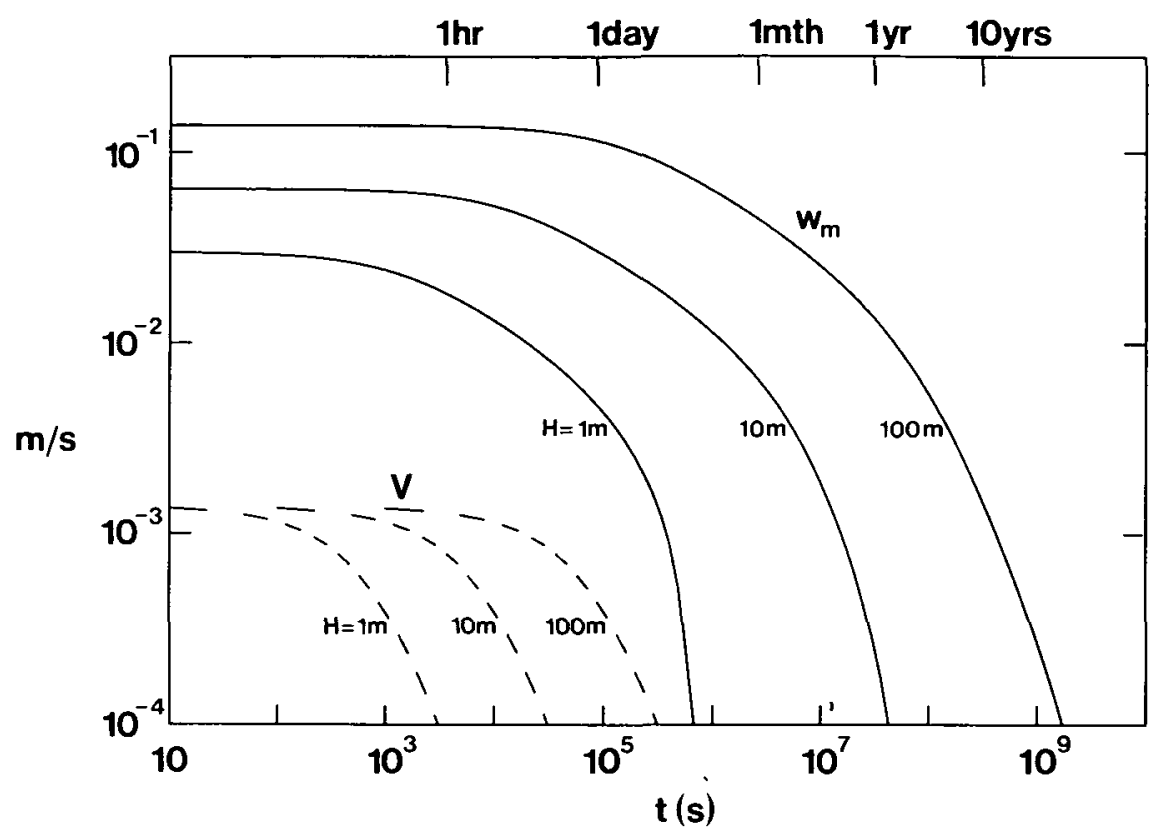

FIG. 14. The root-mean-squared vertical velocity at the centre of the komatiite lavas as a function of time for the same cases as considered in Fig. 13. The dashed curves represent the Stokes free-fall velocity $V$, given by (31), for an olivine crystal with $l=1 \mathrm{~mm}$ and $\Delta \rho=500 \mathrm{~kg} \mathrm{~m}^{-3}$ given by (31).

where $\Delta \rho$ is the density difference between the crystal and liquid and $l$ is a typical length scale (radius for spheres) of the crystal.

Figure 14 shows the variation of convective velocity $w_{m}$ with time, for three lava depths assuming that cooling is governed by heat loss throughout a thin crust according to the eutectic model (see Appendix C3 for details). Also shown are the variations of settling velocity of olivine crystals with a diameter of $1 \mathrm{~mm}$. The olivine settling velocities decrease more rapidly than the convective velocity, because of the much stronger dependence of settling velocity in comparison to convective velocity on viscosity. The calculations suggest that olivines will usually be kept in suspension in the early stages of cooling while the interior lava is vigorously convecting. As the spinifex zone thickens, however, we anticipate that the convective motions will decrease in vigour so that the variation of velocity with time will depart from these calculations. Present understanding of the behaviour of solid particles in thermally convecting fluid layers is also poor. We therefore interpret these results with caution. Continuous settling from the base of the convecting layer may be possible since the velocities calculated with equation (3) refer to the centre of the fluid layer and the velocities will decrease towards the solid lower boundary. The calculations raise the question of whether a settling model is in fact the correct explanation of the cumulate B-layer. This issue is discussed further in the next section.

\section{GEOLOGICAL IMPLICATIONS}

We now discuss the origin of compositional and textural zoning in komatiites in the light of our experimental and theoretical results. The physical constraints on the origin of the principal features of typical zoned komatiites are considered. We discuss possible causes of deviations from the common pattern. We also discuss interpretations of the geochemical profiles taken through differentiated komatiites. 


\subsection{Chilled margins}

Chilled margins have been recognized at the top and sometimes at the bottom of flow units. The upper chilled margins are generally observed as an entirely glassy layer underlain by thick, fine-grained, randomly oriented spinifex olivine crystals set in a glass matrix. The outer quench zone is typically thin (a few millimetres to a few tens of centimetres) and is therefore consistent with our calculations that a thin quench zone should form very rapidly (see Appendix C3). These materials provide the closest indication of the liquid composition of the lava as it is emplaced, if they are free from dispersed phenocrysts and have escaped alteration.

\subsection{Spinifex A-layer}

We suggest that oriented spinifex texture develops in a manner similar to that observed in our experiments and depicted schematically in Fig. 2. Initially many crystals nucleate at the roof and grow in many different directions. However, compositional convection from these growing crystals plays an important role in the subsequent processes. A pool of stratified, differentiated melt forms around the crystais. As this pool grows in depth crystals originally growing perpendicular to the roof are favoured. Such crystals extend below the stratified solute-poor fluid into the convecting solute-rich lava. Smaller crystals, or those with unfavourable initial orientations, are stranded in the stratified zone and grow less rapidly. Eventually a small number of favoured crystals grow perpendicular to the roof to form large platy crystals whose tips are immersed in solute-rich convecting fluid. Growth of the crystal in the horizontal direction is inhibited because they are surrounded by differentiated melt. Thus compositional convection creates a favourable environment in which oriented spinifex texture can develop.

Some detailed features of komatiite A-layers are consistent with this model. In the flows of Munro Township and Alexo area (Arndt et al., 1977; Arndt, 1986) olivine compositions become somewhat more Fe-rich towards the base of the A-layer, which is commensurate with the olivine dendrites growing into a lower convecting layer that becomes increasingly differentiated with time as it cools and crystallizes. However, Arndt et al. (1977) and Arndt (1986) have also shown that individual olivine blades in the A-layer are strongly and continuously zoned to Fe-rich margins. The zoning across individual blades is in fact more marked than the variation of core compositions down through the spinifex zone (Arndt, 1986). These observations could be interpreted as a consequence of the development of an increasingly differentiated and thicker stratified melt layer with time. At any level along a blade the surrounding melt would become more Fe-rich with time leading to normal zoning. In this model the olivine composition in the chilled margin of the flow would be more forsteritic than in the spinifex zone. This is as observed at Alexo (Arndt, 1984).

Well-developed spinifex has not been widely reported from the base of flows or growing upwards from the top of the B cumulate layer. N. T. Arndt (written communication) has observed spinifex olivines growing from the top of the $B_{1}$-layer in komatiites of Mount Clifford, Western Australia, but this relationship is uncommon. We suggest that a number of factors control this asymmetric distribution. First, much of the heat flow occurs through the roof and creates the conditions for nucleation of crystals. Second, compositional convection has an influence in forming an environment in which this texture can develop. Compositional convection cannot produce such stratification on the floor. Third, convection in the lower part of the flow may be sufficiently vigorous to further inhibit nucleation or survival of dendrites against the floor. Fourth, the komatiites at Pyke Hill, Munro Township (Walker, 1971), are interpreted by us as a compound lava flow in which many thin flow units are 
rapidly emplaced one on top of another. In such situations the underlying flows will remain hot and inhibit downwards heat flow. Finally, the lower part of the flow can already be charged with phenocrysts which act as centres for further growth.

The textural features of the spinifex zone are frozen in by crystallization of the interstitial melt, which forms the solid groundmass of fine skeletal and feathery clinopyroxenes and glass. The compositions and textures of the clinopyroxenes suggest sudden nucleation from a supercooled liquid resulting in an abrupt transition from a low viscosity liquid to a solid. We suggest that this front of solidification will advance downwards in a manner similar to the eutectic front in our experiments.

Some lavas described by Pyke et al. (1973) and Arndt et al. (1977) lack a spinifex zone and are massive units containing dispersed equant olivines. Arndt et al. (1977) showed that the flows with well-developed spinifex can pass laterally into these massive types. A simple explanation of this would be to invoke the emplacement of another flow unit on top of the first flow before the spinifex had developed. This would effectively insulate the flow from cold sea water, decreasing heat flow through the roof and inhibiting spinifex development. If the komatiites at Pyke Hill can be interpreted as a compound lava in which successive units were emplaced on top of one another in the same eruption, the development of spinifex zones could well depend on the rate of emplacement of successive lava units.

Another deviation from the type section is shown by flows which are entirely composed of randomly oriented spinifex. Examples include the $21 \mathrm{~m}$ thick Murphy Well flow (Lewis \& Williams, 1973) and certain flows in the Abitibi belt at Destor township in Quebec (L. Gelinas, pers. comm.). We suggest that such units could be formed from the emplacement of strongly undercooled crystal-free lavas. Conditions for development of strong undercooling were given in Part $I$ in flows with low flow rates which can cool initially at rates of over $1000^{\circ} \mathrm{C} \mathrm{h}^{-1}$. Such lavas could be emplaced and ponded sufficiently quickly that delays in olivine nucleation are anticipated.

\subsection{Cumulate B-layer}

At first sight the origin of the peridotite B-layer of cumulate olivine crystals is straightforward and is widely accepted as being by crystal settling (Arndt et al., 1977; Donaldson, 1982). However, detailed studies of some komatiite units show features inconsistent with just a simple settling model, requiring the involvement of additional effects. One flow from Munro Township shows reverse grading of olivine crystals (Arndt et al., 1977). Some flow units can also show a decrease in modal olivine content and $\mathrm{MgO}$ content towards the base of the B-layer (Arndt et al., 1977; Viljoen et al., 1983). In some flows from Munro Township (Arndt et al., 1977) the proportions of olivine do not seem to be great enough to form a touching crystal framework. In addition our theoretical analysis of settling raises the questions of when and if olivine crystals can settle from the thermally convecting lower layer.

Three models are considered here for the origin of the B-layer, none of which are entirely consistent with the observed relationships. The third model does not involve settling at all and is a new concept for the development of the B-layer, since it relies on the contemporaneous formation of the sponifex zone in the upper part of the flow.

Model I involves the emplacement of komatiite with suspended equant olivine crystals. Thermal convection keeps these crystals mixed uniformly throughout the flow, except near the top and base. As the convection declines in vigour and the crystals increase in size a critical condition is met where mass sedimentation occurs. This model would explain the lack of cryptic variation in the B-layer through Munro Township flows and the zoning of individual crystals. Crystals would be circulated throughout the convecting layer and would 
become zoned as the residual liquid differentiated. Reverse grading would not be expected, however.

Model II envisages progressive settling of the crystals. Crystals near the base of the flow would be in a region of lower velocities and could settle out as the flow evolves with time. This model was favoured by Arndt et al. (1977). Crystals that fall out early would be small and conditions would be favourable for settling, because of the lower viscosity at this stage. With time the crystals grow larger, but settling is also inhibited by the increasing viscosity. Reverse grading would be expected. However, cryptic layering would also be anticipated and, as with Model I, an increasing modal content of olivine would not be predicted. It is also by no means clear that either settling model would be physically viable. In one Munro Township example the olivines only range from 0.3 to $0.7 \mathrm{~mm}$ diameter and convective velocities far exceed their settling velocities over the whole span of the flow in the early stages of cooling. Since we cannot yet model the complete cooling history of a komatiite, it is not certain at what stage convective velocities would be small enough to allow settling.

Model III is based on the present experimental studies and is a natural consequence of the mechanism proposed for spinifex formation (Fig. 2). In the experiments the stratified differentiated layer grows at the expense of the lower convecting layer. This occurs because of the growth at the crystal tips immersed in the lower convecting layer and thereby differentiated fluid is transferred from the lower layer to the upper layer. In the case of a komatiite we envisage equant olivines also growing in the convecting layer at the same time as the spinifex zone develops. The consequence of removal of residual fluid by compositional convection to the upper layer must be to concentrate progressively the crystals in the lower layer, since they cannot be transferred up through the interface. This mechanism could logically continue until the concentration of crystals approaches 70 per cent (random loose packing). Convective motions would cease before such high concentrations were attained.

This non-settling mechanism can be quantitatively evaluated. A 30 per cent $\mathrm{MgO}$ komatiite liquid will crystallize $40-50$ per cent olivine in cooling from 1600 to $1200^{\circ} \mathrm{C}$. Only 20-30 per cent of the liquid layer need be transferred upwards in order to raise the final concentration to 70 per cent olivine. In those flows where the A- and B-layers are comparable in thickness this mechanism could be important and it avoids the possible theoretical difficulties.

This model provides an explanation for an enigmatic feature of the komatiites documented by Arndt et al. (1977). In those flow units with no spinifex zone the modal olivine content often only reaches $45-55$ per cent, whereas the olivine content can be up to 70 per cent in a flow with a well developed spinifex zone. This relationship is also evident even within a single flow, which changes laterally from one kind to another. The olivine crystals in the spinifex-free zone are of uniform size. Modal content of less than 65 per cent are not sufficient to produce a grain-supported sediment and some individual crystals appear isolated. This observation casts further doubt on the viability of crystal settling. In contrast to this, beneath spinifex-textured zones, the modal content of olivine in the B-layer reaches values of 60-70 per cent and displays grain-supported textures.

The $\mathrm{B}_{1}$-layer is also enigmatic. It occurs as a thin layer of horizontally aligned acicular or hopper crystals at the top of the B-layer. Observations by N. T. Arndt and R. S. J. Sparks on komatiites of the Abitibi belt indicate that the thick $B_{1}$-layer development occurs in those flows with a well-developed oriented spinifex zone. A very similar layer developed in our experiments in which early dendritic crystals nucleated at the roof and then fell off, settling on their side on the floor (see Fig. 5). If this were the correct explanation for komatiite $B_{1}$-layers then the B-layer would have to settle out before the development of the A-layer. This is indeed the conventional view, but is hard to reconcile with the difficulties of settling at 
an early stage. There is also an important difference in the properties of the laboratory experiments. The settling velocities are typically 100 times greater than convective velocities in aqueous solutions and thus settling is always important in laboratory situations. We suggest that a more appropriate explanation is the following.

Evidence from Munro and La Motte Townships is in fact consistent with the idea that the spinifex zone develops before the B-layer has finally accumulated. In the Pyke Hill komatiite (Arndt et al., 1977) 15 per cent of the olivines distributed throughout the B-layer are acicular with typical widths of $0.3 \mathrm{~mm}$ and lengths of $1.5 \mathrm{~mm}$. In La Motte Township the B-layers also contain some skeletal crystals and xenoliths of spinifex-textured rock as well as equant olivines. These crystals and xenoliths could be due to fall of material from the developing spinifex zone into the lower convecting layer.

The above considerations suggest that the $B_{1}$-layer in fact forms at a late stage towards the end of the accumulation of the main B-layer and the development of most of the A-layer. At this stage the remnant convecting layer will have become thin and must eventually decrease in thickness sufficiently for its Rayleigh number to fall in the range $10^{3}$ to $10^{6}$. Under these conditions a more regular steady pattern of convection cells should develop prior to complete solidification. This would involve sluggish horizontal flow along the top of the B-layer to feed narrow rising plumes. At low Rayleigh numbers the regions of uprising and falling plumes will become fixed. The $B_{1}$-layer could therefore represent fragments of acicular spinifex crystals aligned in this late-stage circulation.

\subsection{Geochemical profiles}

The various differentiation mechanisms described in the experiments and discussed above result in large variations of chemical composition across komatiites. Figure 15 shows some examples of geochemical profiles through several flows, which can be usefully compared with profiles across the experimental products (Figs. 6, A2 and A5). There are a number of similarities between the laboratory and natural profiles, which provide further evidence for the operation of compositional convection in komatiites.

Both sets of profiles show upper thin quench margins which have the same composition as the initial liquid. Both sets of profiles show strong enrichment in the chemical components incorporated in the crystals within their lower parts. In each case this can be attributed to an accumulation of crystals in the lower half either by settling or the concentration process envisaged in Model III. Within the experimental products the bulk composition of the solid material at the upper part of the spinifex zone is slightly depleted in the crystallizing components for the $\mathrm{Na}_{2} \mathrm{CO}_{3}$ and $\mathrm{Na}_{2} \mathrm{SO}_{4}$ systems, but is possibly slightly enriched in the $\mathrm{KNO}_{3}$ system. This suggests that the main part of a spinifex zone in a komatiite does not generally represent a liquid composition. Geochemical arguments for this view have been given by Arndt (1986) and Barnes et al. (1984).

A prominent feature of the compositional profiles in komatiites is the presence of a depleted zone towards the base of the A-layer. The same feature is seen in all the experimental profiles and is a direct consequence of compositional convection. In the experiments the layer of solute-poor fluid thickens with time and advances towards the base of the container as the eutectic front advances behind it. This layer of differentiated solute-poor liquid is eventually frozen in at the bottom of the dendrite layer. The presence of this differentiated zone was seen in the $\mathrm{KNO}_{3}$ experiment as a layer rich in red dye, which coincides with the zone depleted in $\mathrm{KNO}_{3}$ (see Appendix A2). We attribute the depleted zone in komatiites ta the same process in which a static layer of stratified differentiated fluid develops and is ultimately trapped in the central parts of the flow which is the last material to crystallize. 

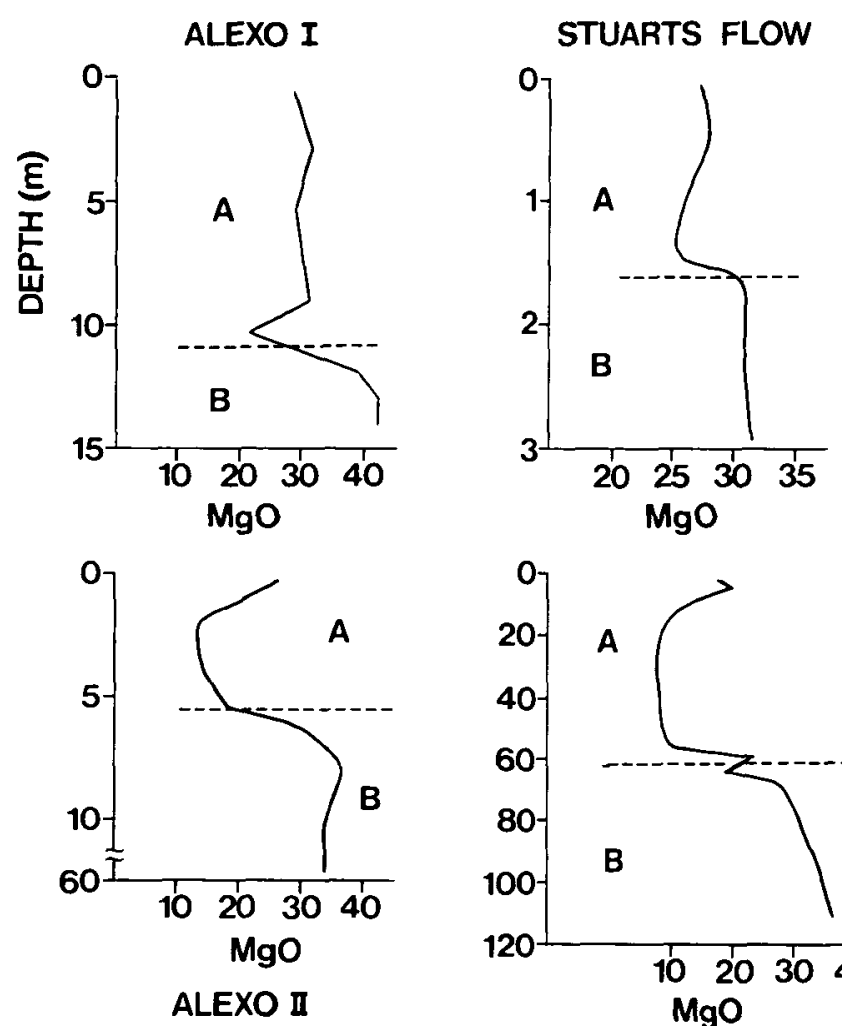

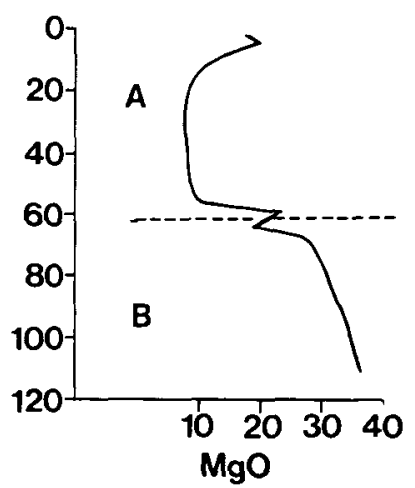

FREDS FLOW

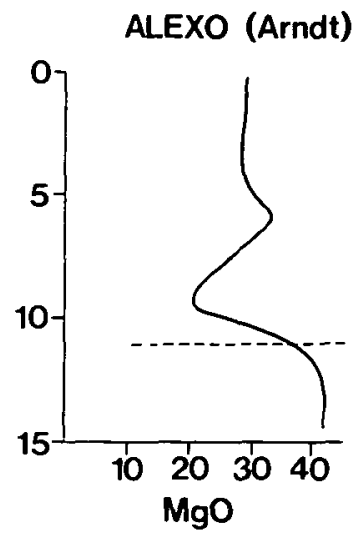

FIG. 15. The MgO concentration as a function of depth for various outcrops in Northern Ontario, Canada. Notice the similarity between these distributions and those of Figs. 6, 9, A2, and A5.

\section{FINAL THOUGHTS}

Donaldson (1982) provided an excellent review of the progress and problems in understanding the solidification of komatiites. The main feature of crystallization models up to 1982 was that the flows solidified under conditions which were considered to be essentially static and in which heat loss was by conduction and olivines settled out. The major problem in explaining dendritic and skeletal morphologies centred on the observation that the cooling rates or undercoolings required to produce these morphologies are much higher $\left(\gg 1{ }^{\circ} \mathrm{C} \mathrm{h}^{-1}\right.$ ) than those calculated for conductive cooling of all but the thinnest lavas. However, skeletal and dendritic crystals can be found deep in the interior of flow units several metres thick, where conductive cooling rates would be orders of magnitude slower than indicated by the crystallization experiments, even allowing for the ultramafic character of the melts. The experimental studies of Kinzler \& Grove (1984) also indicate that some thick komatiites cooled rapidly and were characterized by unexpectedly high rates of crystallization. Other troublesome features noted in Donaldson's review were: (a) the presence of an interstitial groundmass deep in many flows composed of dendritic and skeletal clinopyroxene set in devitrified glass; (b) the metastable compositions of many primary crystals implying non-equilibrium conditions; and (c) the mysterious absence of crystal settling in non-layered flows.

The principal theories of both Parts I and II are that dynamic effects are critical to 
understanding komatiites and that a completely conductive cooling model is inappropriate. We consider that komatiites should be interpreted within the conceptual framework of forced, thermal and compositional convection as described in these two papers.

The dynamic models of flow, cooling and crystallization resolve some of the major problems recognized by Donaldson. Rapid initial cooling rates and large undercoolings, compatible with experimental studies, are predicted both during flow and after emplacement. The textural and mineralogical anomalies cited above can thus be explained. Our experiments have highlighted the fact that dynamic effects are also important in determining crystal morphologies. Thus the results of Donaldson's investigations $(1976,1979)$, obtained under static conditions, can be expected to be modified under dynamic conditions. When appropriate dynamic conditions exist, dendritic morphologies may be possible at cooling rates and undercoolings which are much less than the values indicated by static experiments. We suggest, as did Donaldson (1982), that the A- and B-layers could well form at the same time. The different morphologies reflect dynamic conditions, with the development of platy dendrites being influenced by being in a statically stratified region of their own creation, while equant suspended olivines are precipitating from a vigorously convecting layer. Finally both geological observations and theory cast doubt on the role of crystal settling. It may be that those flows with unsettled crystals are in fact explicable and that the concentration of crystals in the B-layer is due to the contemporaneous development of a spinifex zone rather than settling.

\section{ACKNOWLEDGEMENTS}

The experiments were carried out at the Research School of Earth Sciences of the Australian National University, Canberra. We acknowledge with thanks the efficient technical assistance of R. Wylde-Browne, J. Micallef and D. Corrigan and also thank E. Kiss and W. Ullman for the analyses of experiment B. RSJS and HEH were Visiting Fellows at $A N U$ at the time the initial experiments were done and they are grateful for support from ANU, the Anglo-Australian Fellowship scheme and by the Maurice Hill Fund. Discussions with N. T. Arndt, M. J. Bickle, L. Gelinas, O. Strecher and I. H. Campbell provided considerable stimulation to the studies since that time. Reviews of the paper by $\mathrm{C} . \mathrm{H}$. Donaldson, C. Ford, J. M. Duke and A. R. McBirney are acknowledged with pleasure. M. A. Hallworth and J. M. Wheeler helped to prepare the figures, for which we are grateful. Our research is sponsored by grants from the B.P. Venture Research Unit and the N.E.R.C. Finally, R.S.J.S. acknowledges support by the Tyrrell Burr Canada Fund of the Geological Society to carry out field observations of komatiites in Canada.

\section{REFERENCES}

Arndt, N. T. 1986. Differentiation of komatiite flows. J. Petrology, 27, 279-301.

Naldrett, A. J., \& Pyke, D. R., 1977. Komatiitic and iron-rich tholeiitic lavas of Munro Township, Northeast Ontario. Ibid., 18, 319-369.

— \& Nesbit, E. G., 1982. Komatiites. Allen \& Unwin, 526 pp.

Barnes, S. J., Gorton, M. P., \& Naldrett, A. J., 1983. A comparative study of olivine and clinopyroxene spinifex flows from Alexo, Abitibi Greenstone Belt, Ontario, Canada. Contr. Miner. Petrol. 83, 293-308.

Bickle, M. J., 1982. The Magnesium Contents of Komatiitic Liquids. Arndt, N. T., \& Nisbet, E. G. (eds.). Allen \& Unwin, Chapter 27, 479-494.

Chen, C. F., \& Turner, J. S., 1980. Crystallization in a double-diffusive system. J. geophys. Res. 85, 2573-2593.

Deardorff, J. W., \& Willis, G. E., 1967. Investigation of turbulent thermal convection between horizontal plates. J. Fluid Mech. 28, 675-704.

Donaldson, C. H., 1976. An experimental investigation of olivine morphology. Contr. Miner. Petrol. 57, 187-213. 1979. An experimental investigation of the delay in nucleation of olivine in mafic magmas. Ibid, 69, 21-32.

- 1982. Spinifex-textured komatiites: a review of textures, compositions and layering. In Komatiites. Arndt, N. T., \& Nisbet, E. G. (eds.). Allen \& Unwin, Chapter 16, 213-244. 
Huppert, H. E., \& Sparks, R. S. J., 1985. Komatiites I: eruption and flow. J. Petrology, 26, 694-725.

Turner, J. S., \& Arndt, N. T., 1984. Emplacement and cooling of komatiite lavas. Nature, 309, 19-22.

Jaeger, J. C., 1968. Cooling and solidification of igneous rocks. In Hess, H. H., \& Poldervaat, A. (eds.). Basalts, Volume 2.

Kerr, R. C., \& Turner, J. S., 1981. Layered convection and crystal layers in multicomponent systems. Nature, 298, $731-733$.

Kinzler, R. J., \& Grove, T. L., 1984. Crystallization and differentiation of Archean komatiites from northeast Ontario: phase equilibrium and kinetic studies. Am. Miner. 70, 40-51.

Lewis, J. D., \& Williams, I. R., 1973. The petrology of an ultramafic lava near Murphy Well, Eastern Goldfields, Western Australia. A Rep. Geol. Surv. W. Aust., 60-68.

Nisbet, E. G., Bickle, M. J., \& Martin, A., 1977. The mafic and ultramafic lavas of the Belingwe greenstone belt, Rhodesia. J. Petrology, 18, $521-566$.

Pyke, D. R., Naldrett, A. J., \& Eckstrand, O. R., 1973. Archean ultramafic flows in Munro Township, Ontario. Geol. Soc. Am. Bull. 84, 955-978.

Simonson, J. R., 1975. Engineering Heat Transfer. Macmillan, $257 \mathrm{pp}$.

Turner, J. S., 1979. Buoyancy Effects in Fluids. Cambridge University Press. 1980. A fluid-dynamical model of differentiation and layering in magma chambers. Nature, 285, 213-215.

- \& Gustafson, L. B., 1981. Fluid motions and compositional gradients produced by crystallization on melting at vertical boundaries. J. Volcanol. Geotherm. Res. 11, 93-125.

Usselman, T. M., Hodge, D. S., Naldrett, A. J., \& Campbell, I. H., 1979. Physical constraints on the characteristics of nickel-sulphide ore in ultramafic lavas. Can. Miner. 17, 361-372.

Viljoen, M. J., Viljoen, R. P., Smith, H. S., \& Erlank, A. J., 1983. Geological, textural and geochemical features of komatiitic flows from the Komati Formation. Special Publication No. 9, Geol. Soc. South Africa, 1-20.

Walker, G. P. L., 1971. Compound and simple lava flows and flood basalts. Bull. Volcanol. 35, 579-590.

Worster, M. G., \& Leitch, A., 1985. Laminar free convection in confined regions. J. Fluid Mech. 156, $301-19$.

\section{A PPENDIX A: Experimental observations with different solutes and concentrations}

\section{A.1. Systematic changes with initial concentration}

Experiments using $\mathrm{Na}_{2} \mathrm{CO}_{3}$ solutions with concentrations above and below that used in the case described in Section 2.2.1. (and also the eutectic composition) have shed further light on the physical factors influencing the development of crystallization. The major features and inferences remain unchanged, however.

As the initial concentration of $\mathrm{Na}_{2} \mathrm{CO}_{3}$ increased, so too did the influence of the upper stable fluid layer. Near the eutectic composition of 5.93 wt. per cent $\mathrm{Na}_{2} \mathrm{CO}_{3}$ (run $\mathrm{G}$, a case which is considered in more quantitative detail in Section 2.3. and Appendix C2) there was no stable layer. The composition of the fluid did not change during crystallization, so that convection due to cooling at the top dominated and extended through the depth of the fluid. In run $\mathrm{E}$, at a concentration of 9.5 per cent $\mathrm{Na}_{2} \mathrm{CO}_{3}$, crystals were growing and releasing less dense fluid, but strong convection was observed below the roof during the early stages of growth so that the density changes due to cooling were still more important than those due to compositional differences. At a concentration of 12.3 per cent (run A, already described) the stable layer was established, although we cannot predict quantitatively at what point the compositional changes should outweigh the thermal effects. In run $\mathrm{C}$, with a concentration of 14.8 per cent $\mathrm{Na}_{2} \mathrm{CO}_{3}$ the stable fluid layer was firmly established; no convection was visible below the top crystals, and this remained true for higher concentrations. Increasingly strong compositional convection was observed above the crystals growing on the bottom as the concentration was increased, and a temperature rise was detected, due to the release of latent heat. This aspect was better documented in runs using other solutes, as described below.

Over the range of concentrations covered, the ratio of rates of advance of the dendritic crystal layer and the eutectic layer also changed systematically, as shown in Fig. Al. The average rates over the first hour have been used; during this time the growth rate of the eutectic differed little between runs, and the main change was in the growth rate of the dendrites. The implication is that the level at which the eutectic temperature, $-2 \cdot 1^{\circ} \mathrm{C}$, was reached propagated at a rate independent of the fluid composition, while the dendrites grew more rapidly as the external composition approached the composition of the dendrites ( 37 per cent $\mathrm{Na}_{2} \mathrm{CO}_{3}$ ). This comparison could not be simply pursued at later times because of the accelerated and irregular growth of the crystals. In run $\mathrm{L}$, a small fraction of $\mathrm{K}_{2} \mathrm{CO}_{3}$ was added to the $\mathrm{Na}_{2} \mathrm{CO}_{3}$ solution, but this should not invalidate the comparison made here. Run $\mathrm{D}$ is a case where crystals were deliberately allowed to form and fall to the bottom before growth on the roof was established, and this aspect will be discussed further below. 


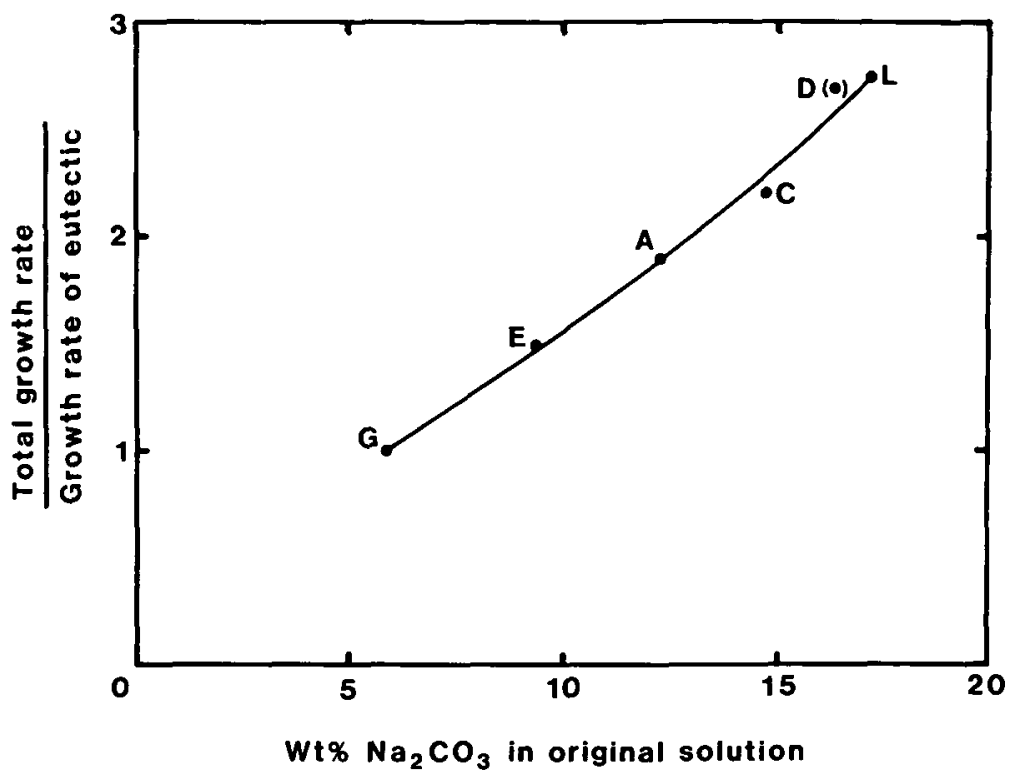

FIG. A1. The rate of growth of the crystal front compared with that of the following eutectic layer for the experiments using $\mathrm{Na}_{2} \mathrm{CO}_{3}$ with different initial concentrations.

In Fig. A2 we compare the vertical concentration profiles measured at the end of each of the experiments with pure $\mathrm{Na}_{2} \mathrm{CO}_{3}$ solutions. This is plotted in a slightly different form to Fig. 6; it has been assumed that the solid mass consists either of pure $\mathrm{Na}_{2} \mathrm{CO}_{3} \cdot 10 \mathrm{H}_{2} \mathrm{O}$, or the eutectic mixture, and the results are expressed as wt. per cent of the hydrated crystals. Also most of the experiments were conducted using a nominal (initial) depth of $80 \mathrm{~mm}$, and the profile for run $\mathrm{A}$ has been scaled to make it directly comparable with the others. Profiles $\mathrm{C}$ and $\mathrm{E}$ are very similar to $\mathrm{A}$ and only the novel features of $D$ and $G$ will be remarked on here. The 'eutectic' profile $G$ has a small increase of concentration at the bottom, corresponding to a few crystals which were observed to grow there at a late stage in the experiment, and a minimum (below the eutectic concentration) just above this; both these must be due to non-equilibrium effects.

In run $\mathrm{D}$ (with 16.4 per cent $\mathrm{Na}_{2} \mathrm{CO}_{3}$ ) the experiment was started with a thin ( $5 \mathrm{~mm}$ deep) layer of kerosene between the $\mathrm{Na}_{2} \mathrm{CO}_{3}$ solution and the cooled roof. This promoted strong cooling and crystallization, but the crystals could not stick to the roof, and instead formed large sheets or rafts at the interface. These detached themselves intermittently, and fell to the bottom, where they promoted further crystallization, with strong compositional convection above it. After about $20 \mathrm{~min}$, the fluid level was raised to touch the roof (by forcing out the kerosene) and crystals plus eutectic began to grow downwards, (but starting with a lower concentration because of the crystals removed to the bottom). The large influence of the settled crystals, extending halfway up the tank, is seen in profile D of Fig. A2; the anomalous point can be attributed to poor horizontal sampling, through one of the large sheets of crystals falling from the roof. These features can be seen in the photograph of Fig. A3, which should be contrasted with Fig. 5 (run A) in which the layer of crystals on the bottom was much thinner.

\section{A.2. Experiments using other solutes: $\mathrm{KNO}_{3}$}

In one of our earliest experiments, subsequently called run $0, \mathrm{KNO}_{3}$ solution was used with S.G. 1.175 at $23^{\circ} \mathrm{C}$. The tank was filled to $125 \mathrm{~mm}$ with $6 \mathrm{~mm}$ diameter glass balls (with a porosity of about 38 per cent), leaving $75 \mathrm{~mm}$ for the fluid layer above. A wire grid was attached under the roof of the tank to hold the crystals as they formed at temperatures greater than the eutectic temperature $\left(-3.0^{\circ} \mathrm{C}\right)$, and the coolant temperature was brought down from room temperature to $-10^{\circ} \mathrm{C}$ as it was pumped through the lid. Crystals began to form and fall to the top of the glass balls after about 9 min and shortly after this some nucleated on the grid and remained attached.

An advantage of $\mathrm{KNO}_{3}$ is that the density of the (anhydrous) crystals is very different from that of the 


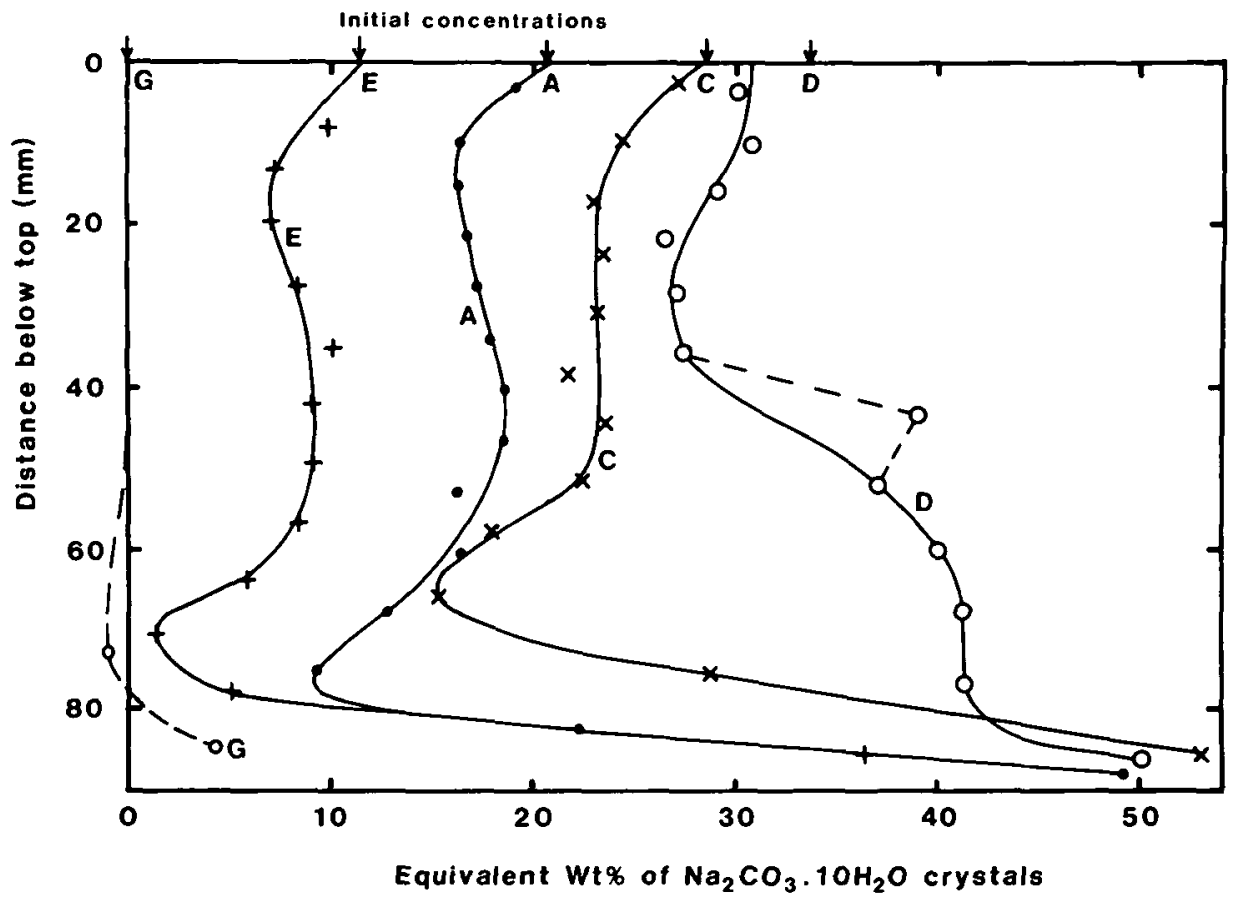

FIG. A2. The vertical concentration profiles measured by sampling the solid crystal+eutectic blocks in all the experiments with pure $\mathrm{Na}_{2} \mathrm{CO}_{3}$ solution. The resuits are expressed as equivalent wt. per cent $\mathrm{Na}_{2} \mathrm{CO}_{3} \cdot 10 \mathrm{H}_{2} \mathrm{O}$ crystals, assuming the remainder to be of eutectic composition. The original concentrations, expressed in the same terms, are shown by the arrows at the top.

solution, so a light layer of residual fluid readily built up, and a sharp interface with the underlying fluid became apparent at $25 \mathrm{~min}$. Red dye injected into the upper layer after $2 \mathrm{~h}$ spread only slowly sideways, showing that this layer was not convecting vigorously. However, near the interface with the lower layer, streamers of dye were sheared out rapidly as they interacted with convective plumes due to compositional and thermal convection in the lower layer. The latter spread out horizontally beneath the interface and produced a viscous shear which was transmitted to the upper layer. Again the crystals growing downwards from the roof were oriented nearly vertically, and their tips extended beyond the interface into the convecting layer below.

After $3 \mathrm{~h}$ a eutectic (ice plus $\mathrm{KNO}_{3}$ ) layer began to form at the roof and advance downwards. After $6 \mathrm{~h}$ the eutectic was $17 \mathrm{~mm}$ thick, and the bottom of the upper layer (dyed red) was $45 \mathrm{~mm}$ from the roof, with a gap of about $13 \mathrm{~mm}$ to the tips of the crystals growing on the bottom. At this time, green dye was injected into the interstitial fluid just below the top of the layer of glass balls. Within a few minutes, a plume of dye rose into the lower convecting layer, and spread out just below the interface with the upper stable layer. We would expect such quasi-horizontal convective motions to persist as the gap becomes much narrower, with the return flow occurring more diffusely through the lower porous layer $\mathbb{N}$ of crystals. At $11 \frac{1}{2} \mathrm{~h}$, the eutectic layer was $22 \mathrm{~mm}$ thick, and the red-dyed fluid layer had grown down $\vec{\circ}$ to $75 \mathrm{~mm}$, the level of the interface with the balls. The experiment was subsequently monitored less frequently, and at some stage between 24 and $36 \mathrm{~h}$, eutectic mixture began to form on the bottom, in the topmost parts of the layer of balls and between the accumulated crystals above them. This zone solidified and grew upwards and eventually (between 36 and $44 \mathrm{~h}$ ) the top and bottom eutectic layers met to form a completely solid mixture of eutectic and crystals.

The block of ice and $\mathrm{KNO}_{3}$ crystals was removed and examined (Fig. A4). The uppermost $24 \mathrm{~mm}$ consisted of ice and crystals free of red dye. The zone between 24 and $52 \mathrm{~mm}$ from the top was coloured pink, and there was a deep red line at $41 \mathrm{~mm}$ depth. Below $52 \mathrm{~mm}$ the structure contained green dye, and the ice extended to $20 \mathrm{~mm}$ beneath the surface of the balls. From these observations, and the subsequent analysis of concentration as a function of depth (Fig. A5) together with a sketch of the 


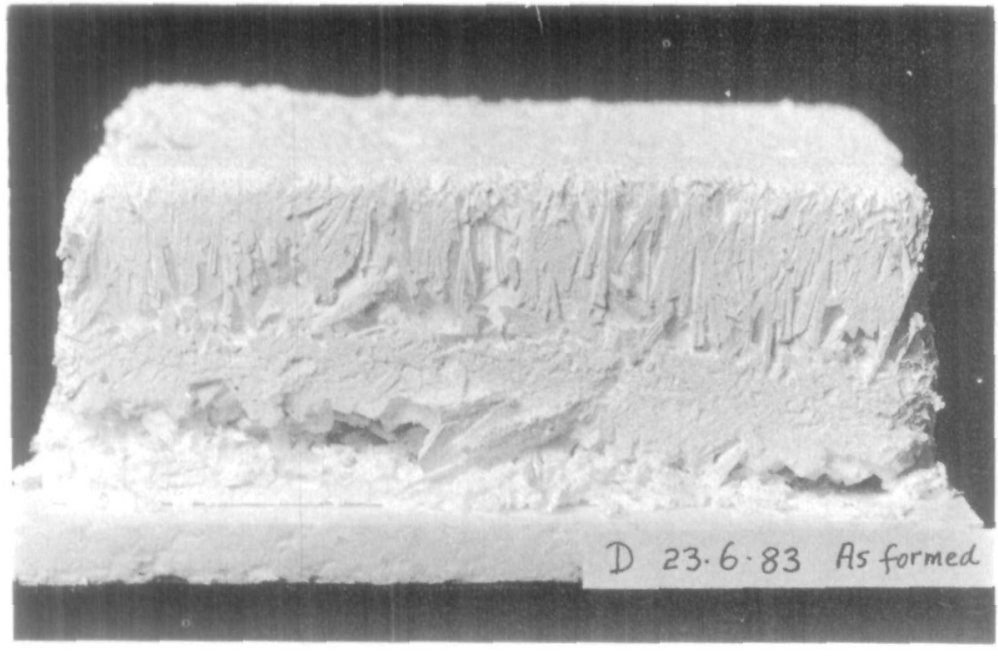

Wt\% $\mathrm{KNO}_{3}$
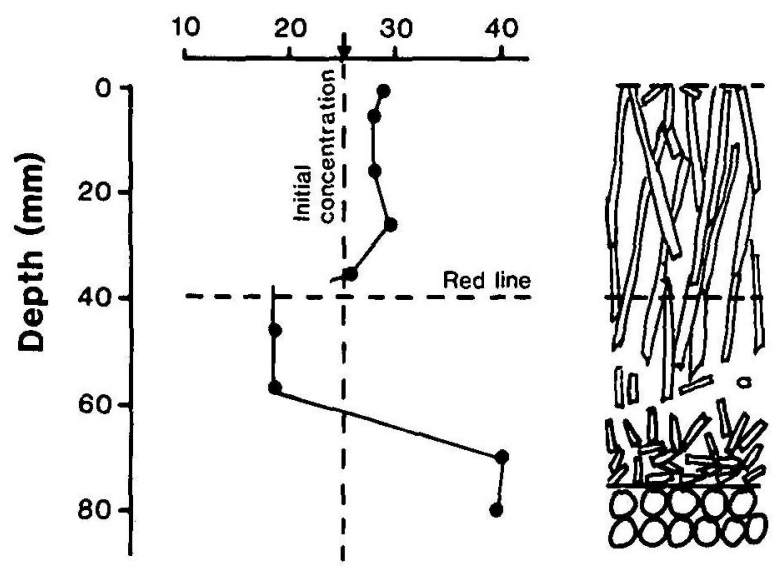

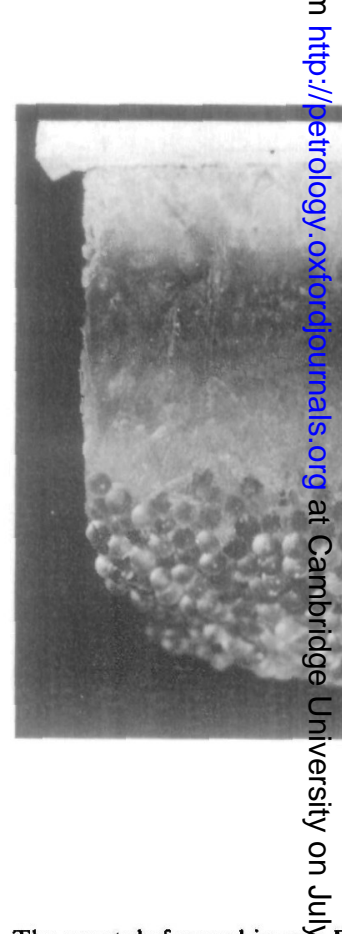

FiG. A3 (top left). The crystals formed in rum D, showing the solid block in the bottom half formed by rafts of crystals falling from the top (contrase with run A, shown in Fig. 5). These falling crystals are probably responsible for the anomalous valupat mid-depth (shown on Fig. A2) as well as the reduction of concentration be $\mathrm{Qw}$ the initial value at the top.

FIG. A4 (above). The final solid block at the end of the experiment using $\mathrm{KNO}_{3}$. This is printed in the orientation in which it grew, with the glass balls at the bottom. The print shows a broad region of dye excluded from the eutectic as it froze, with a sharper, darker line near its centre. (This feature is much clearer on the original colour slide.)

FIG. A5 (bottom left). The concentration profile through the block shown in Fig. A4, with a sketch of the corresponding structure observed during the process of solidification. 
structure, we can make the following deductions. The dominance of crystal growth (without eutectic) caused the $\mathrm{KNO}_{3}$ concentration to be nearly uniform above the red line $(40 \mathrm{~mm})$, and a little higher than that in the original bulk liquid. (We are cautious about asserting that the difference is significant, since this was one of the first experiments carried out and the accuracy was not as great as that achieved in later runs.) There is a minimum below this, in the region which solidified last with a large proportion of eutectic, and the highest $\mathrm{KNO}_{3}$ content is just above the balls where crystals originally settled and grew.

A new feature of particular interest is the behaviour of the dye. This acted as an incompatible element', in the sense that dye molecules were rejected by both $\mathrm{KNO}_{3}$ and ice, and became increasingly concentrated in the residual liquids as the layers of eutectic solid advanced into the interior. Some of the dye evidently could be incorporated into the ice, perhaps trapped within pore spaces, but much was rejected until, at the final stage of solidification, a dye-rich red line at $41 \mathrm{~mm}$ depth marked where the two solid layers met. The samples beneath $52 \mathrm{~mm}$ depth contained trapped green dye whereas those above this contained red dye. This observation shows that the lower solid layer advanced through the interface between the two fluid layers and preserved it in the solid material. These observations also show that once the two layers had formed there was little chemical exchange between them.

\section{A.3. Further experiments with other solutes or mixtures of solutes}

In run $\mathrm{H}$, using $\mathrm{Na}_{2} \mathrm{SO}_{4}$, we attempted to do exactly what has been discussed in Section 2.2.2, using a similar initial temperature and concentration and a pre-cooled roof. We had not yet discovered the difficulties of filling through a hole in the very cold roof, however. During the filling process, the $\frac{\nabla}{\mathbb{D}}$ solution froze and blocked the opening when there was still an air bubble about $90 \mathrm{~mm}$ diameter and $\underset{5}{\overrightarrow{0}}$ $5 \mathrm{~mm}$ deep at the centre, trapped underneath the domed roof. Crystals formed rapidly from the edges inwards, and remained attached to the roof outside the bubble. Small crystals also formed under the air bubble and fell into the convecting fluid below; they were thereby distributed fairly uniformly across $\underset{x}{x}$ the bottom, but with a slightly thicker pile near the centre. After about $40 \mathrm{~min}$ they stopped falling, and $\stackrel{x}{\circ}$ crystallization proceeded from the top and bottom, with again the formation of a horizontal crystal $\frac{0}{0}$ front and a stable fluid layer below the roof.

The significant difference in this case was that the hole at the centre of the crystal mass remained open through most of the experiment. This is a striking confirmation of the near-vertical growth of the $\frac{\omega}{\omega}$ dendritic crystals; where there was initial crystallization on the roof, crystals continued to grow straight $\frac{\text { 응 }}{0}$ down below this, with very little spreading sideways into the clear region. This behaviour meant that temperature measurements made at the centre line were in open fluid, well away from the dendrites. $\stackrel{\vec{O}}{\rightarrow}$ These temperatures confirmed unambiguously that cold but depleted fluid was ponding below the $\stackrel{\otimes}{7}$ roof. For example, after $90 \mathrm{~min}$ when the crystal tips had reached $30 \mathrm{~mm}$, the temperature at $15 \mathrm{~mm}$

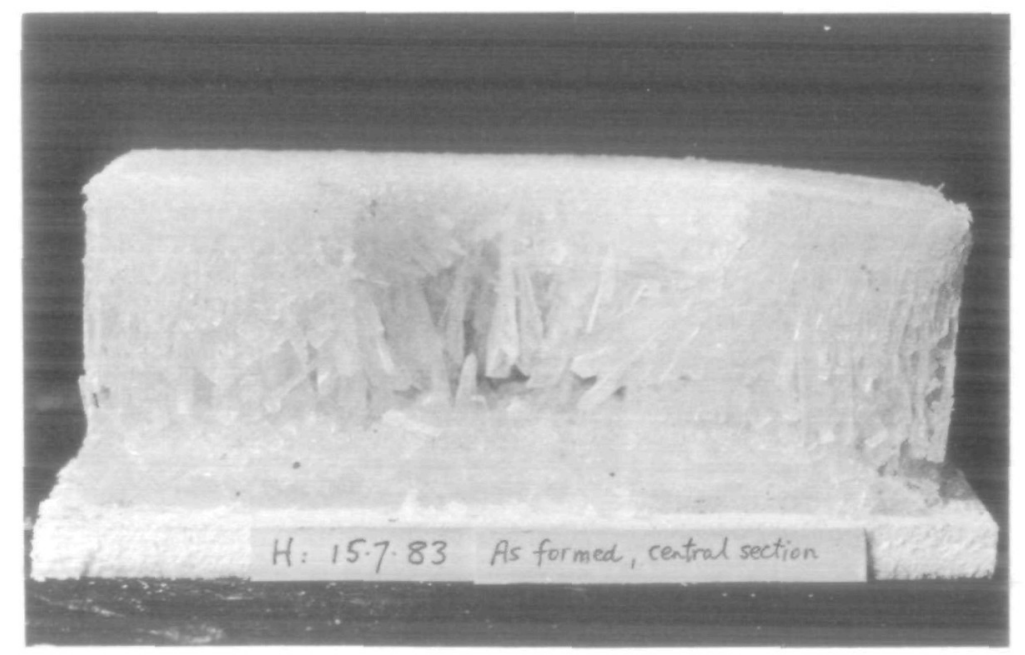

FIG. A6. The crystal block formed in run $H$, showing the hole left below an air bubble trapped at the roof. This hole later filled with solid eutectic, which was allowed to melt and run out before the photograph was taken. 


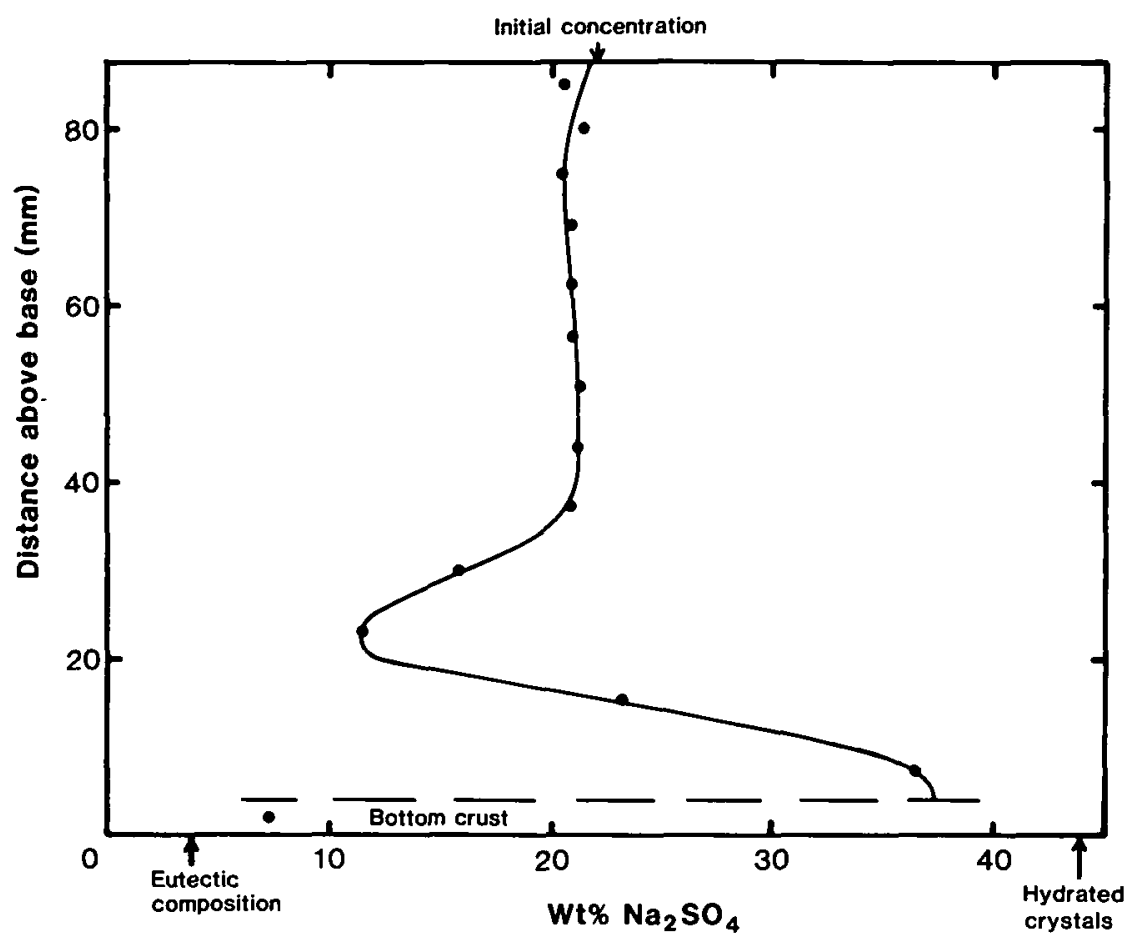

FIG. A7. Profiles of concentration through the solid block of $\mathrm{Na}_{2} \mathrm{SO}_{4}$ and eutectic in run $\mathrm{H}$ (a) at the edge and (b) in the centre, through the hole which later filled up with eutectic. Note (as in Fig. 9) the crust of lower composition at the bottom.

(in the centre of the upper layer) was $8.4^{\circ} \mathrm{C}$ and that at $34 \mathrm{~mm}$ (in the lower convecting layer) was $21.5^{\circ} \mathrm{C}$.

As time went on, a eutectic layer formed below the roof and grew downward, with its horizontal base extending across the central hole as well as between the dendritic crystals. When the block was removed from the tank, sectioned, and the ice allowed to melt, the central portion was left completely open, as shown in Fig. A6. This indication that only eutectic had formed in this region was confirmed by the concentration profiles shown in Fig. A7. (To obtain these we sampled from narrow vertical strips in a central section, at the edge and at the centre, rather than using a single horizontal average.) The central section has eutectic compositions near the top, gradually increasing to the largest values at the fioor (apart from the effect of a thin eutectic crust underneath, which was mentioned in the description of run $\mathrm{K})$. The thickness of the solid crystal layer on the bottom was greater near the centre, reflecting the initial distribution of crystals as they formed and fell below the air bubble. The concentration profile at the edge was similar to those obtained previously, with a sharp minimum just above the solid layer at the bottom, corresponding to the visible gap between the upper and lower crystal masses.

Several exploratory experiments were conducted with mixed solutes, to investigate the behaviour of an 'incompatible element' and also the successive crystallization of several components. For the first purpose, the use of a dye layer (already described, and shown in Fig. A4) was the most satisfactory, since other minor components which we tried were too easily incorporated into the eutectic. For the second purpose, we used a mixed copper sulphate-ammonium sulphate aqueous solution, which had already proved useful in bottom-cooled experiments (Kerr \& Turner, 1981).

We began with a $78 \mathrm{~mm}$ deep layer of mixed solution of S.G. $1 \cdot 237$, initially at $29^{\circ} \mathrm{C}$, and the top was suddenly cooled by pumping coolant at $-30^{\circ} \mathrm{C}$ through the roof. Immediately, fine crystals began to form and to fall to the bottom, with some being carried round and held in suspension by vigorous convection. After about $25 \mathrm{~min}$, the roof was covered with a dense layer of crystals which remained attached, and the crystal layers continued to grow at both top and bottom. At the top, the advancing 


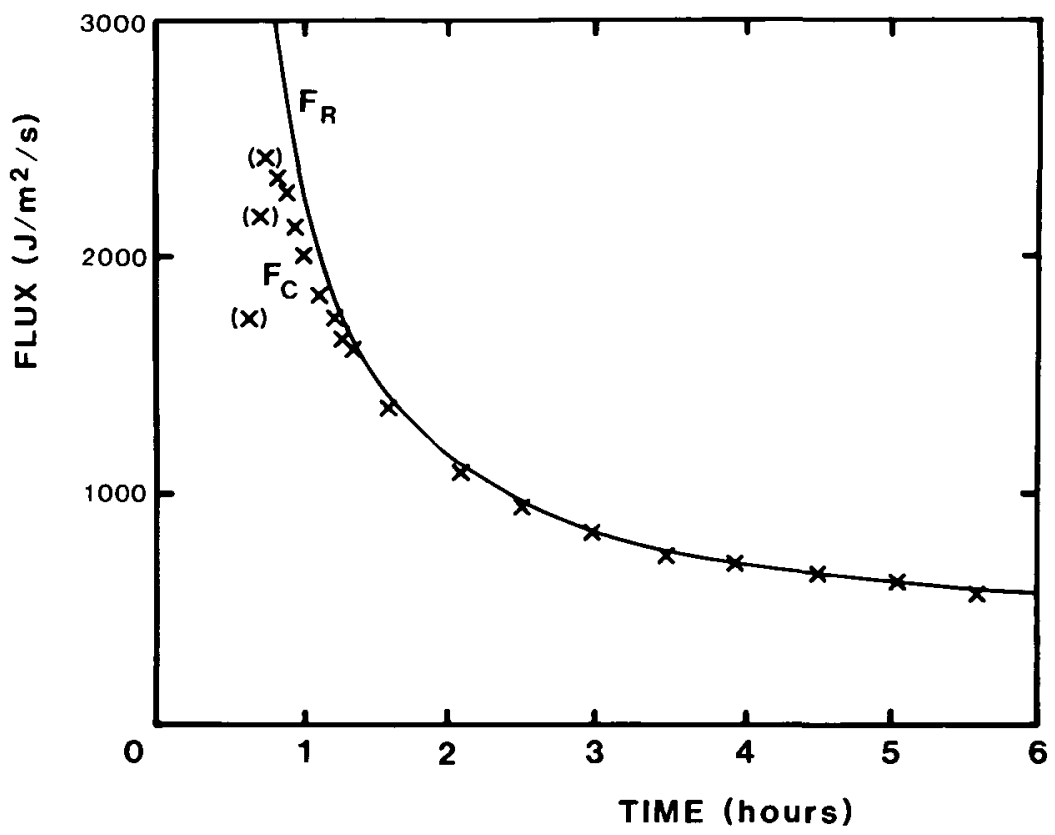

FIG. B1. Comparison of the conductive flux $F_{C}$ through the eutectic layer in run $G$ with the fluxes due to latent heat released as solidification occurs, $F_{\mathrm{L}}$, and to turbulent convective cooling of the fluid below, $F_{\mathrm{T}}$. The curve drawn is the sum of $F_{\mathrm{L}}$ and $F_{\mathrm{T}}$, which should be compared with $F_{\mathrm{R}}$ in Fig. B2.

front of the crystals consisted of a deep blue mixture of fine copper sulphate and the mixed copperammonium sulphate crystals, with a white layer of eutectic filling in behind. A notable difference from the behaviour described previously is that strong downward-streaming motions were observed below the advancing eutectic layer throughout the period which was monitored visually (about $5 \mathrm{~h}$ ), at the end of which the eutectic layer was about $35 \mathrm{~mm}$ thick with $7 \mathrm{~mm}$ of blue crystals ahead of this. The crystal front was very wavy and irregular in thickness, due to the lack of any control by a stable fluid layer, and the crystals were small and close-packed, not dendritic. This points to the existence of compositional convection, due to the removal of a large proportion of water from the solution into the mixed salt $\mathrm{CuSO}_{4} \cdot\left(\mathrm{NH}_{4}\right)_{2} \mathrm{SO}_{4} \cdot 6 \mathrm{H}_{2} \mathrm{O}$ as well as pure thermal convection, since it appeared more vigorous and persistent than in other experiments. There was certainly strong compositional convection above the crystals growing on the floor, which formed a solid mass, with some spikes growing above it in the later stages.

\section{A P PENDIX B: Analysis and discussion of eutectic growth experiments}

When the eutectic layer described in Section 2.3 becomes fully established, the heat flux out of the fluid below will, in a well-insulated tank, be solely by molecular conduction through this solid layer. The heat removed from the fluid is the sum of two terms, due to (a) the convective transfer to the solid from the fluid layer and (b) the latent heat released as the eutectic layer grows.

The three fluxes, calculated as described below, are compared in Fig. B1. (We have also calculated the change in heat storage in the eutectic layer as it thickened, but this was at most a few percent of the other terms.) It has been assumed that the effective temperature at the advancing edge of the eutectic layer is just the eutectic temperature $T_{\mathrm{e}}=-2 \cdot 1^{\circ} \mathrm{C}$. The steady-state conductive flux through a layer of thickness $a$ is then $F_{\mathrm{c}}=K_{\mathrm{c}}\left(T_{\mathrm{c}}-T_{\mathrm{i}}\right) / a\left(\mathrm{~J} \mathrm{~m}^{-2} \mathrm{~s}^{-1}\right)$ where $T_{\mathrm{i}}$, the temperature at the inside of the lid, has been plotted in Fig. 12, and $K_{e}$ is the thermal conductivity of the eutectic, taken to be $1.88 \mathrm{~J} \mathrm{~m}^{-1}$ $\mathrm{s}^{-1}{ }^{\circ} \mathrm{C}^{-1}$. The value quoted is calculated from $K_{\mathrm{o}}=\rho_{\mathrm{s}} c_{\mathrm{p}} \kappa$, where $\rho_{\mathrm{s}}=978 \mathrm{~kg} \mathrm{~m}^{-3}$ is our measured value for the solid eutectic density, $c_{\mathrm{n}}=1.9 \times 10^{3} \mathrm{~J} \mathrm{~kg}^{-1}{ }^{\circ} \mathrm{C}^{-1}$ is the specific heat of ice (Simonson, 1975), and $\kappa=1.01 \times 10^{-6} \mathrm{~m}^{2} \mathrm{~s}^{-1}$ is the thermal diffusivity for the eutectic measured in our laboratory in another series of experiments (Leitch, private communication). There are clearly some uncertainties here; we note that the published value of $\kappa$ for ice is about 20 per cent higher, while we have not been 


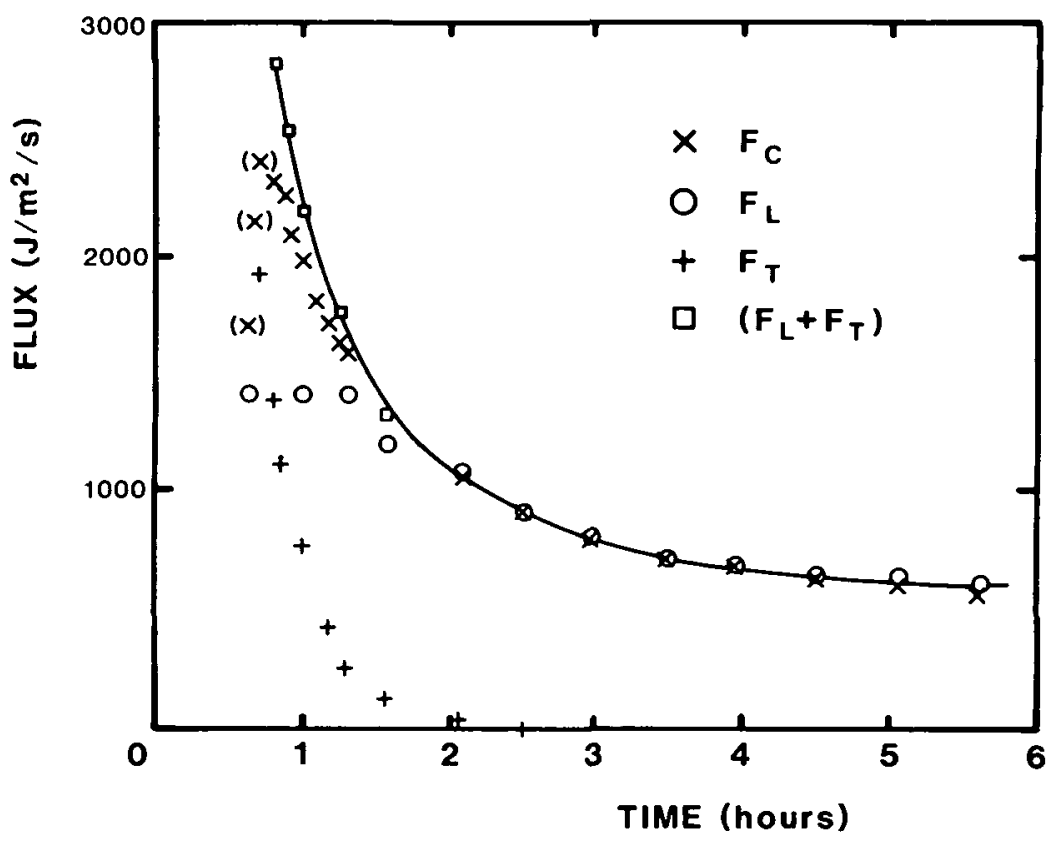

FIG. B2. Comparison of the deduced conductive fluxes at the roof in run $\mathrm{G}: F_{\mathrm{R}}$ is the flux through the insulating sheet separating the outer and inner sections of the roof and $F_{\mathrm{C}}$ is the flux through the eutectic layer. The fluxes have been matched in the interval $2 \frac{1}{2}-5 \frac{1}{2} \mathrm{~h}$, as described in the text.

able to find measurements of $c_{\mathrm{p}}$ for the eutectic. The latent heat term is $F_{\mathrm{L}}=\rho_{\mathrm{S}} L(\mathrm{~d} a / \mathrm{d} t)$, where $\rho_{\mathrm{S}}=$ $976 \mathrm{~kg} \mathrm{~m}^{-3}$ is the density of the solid and $L=3.4 \times 10^{5} \mathrm{~J} \mathrm{~kg}^{-1}$. The cooling term due to turbulent convection has been taken to be $F_{\mathrm{T}}=217\left(T_{\mathrm{f}}-T_{\mathrm{e}}\right)^{4 / 3}$. (The constant has been calculated using the relationship given in Section 3.)

From 2 to $5 \frac{1}{2} \mathrm{~h}$, the convective cooling term $F_{\mathrm{T}}$ is negligible (as we would expect from Fig. 11), and the latent heat $F_{\mathrm{L}}$ and conduction $F_{\mathrm{C}}$ terms are in very satisfactory agreement. Between $40 \mathrm{~min}$ (when the eutectic layer just covered the roof) and $100 \min F_{C}$ was greater than $F_{L}$, as is to be expected when interior convective cooling is also significant. The calculated sum of $F_{\mathrm{T}}$ and $F_{\mathrm{L}}$ is somewhat greater than $F_{\mathrm{C}}$, but very close to the flux through the roof (see below). The first three (low) points for $F_{\mathrm{C}}$ on Figs. B1 and B2 are clearly wrong, due to an overestimate of $a$, and this point will be discussed further below.

It is also useful to compare the conductive flux $F_{\mathrm{C}}$ with the flux ( $F_{\mathrm{R}}$, say) through the solid roof. This latter can be expressed as $F_{\mathrm{R}}=d\left(T_{\mathrm{i}}-T_{\mathrm{o}}\right)$, where $T_{\mathrm{i}}$ and $T_{\mathrm{o}}$ are the temperature at the inner and outer surface of a plastic sheet $0.25 \mathrm{~mm}$ thick inserted between the two parts of the metal roof, and $d$ is a theat flux coefficient' which can be obtained by calibration. Variations of $T_{\mathrm{j}}$ across the roof make this method inaccurate when $T_{\mathrm{f}}-T_{\mathrm{i}}$ is large, but after about $2 \mathrm{~h}$ (in experiment $\mathrm{G}$ ) the estimate of $T_{\mathrm{i}}$ based on the single measurement at the centre gives satisfactory results.

The heat flux $F_{\mathrm{R}}$ calculated on this basis is plotted as the continuous line in Fig. B2, corresponding to $d=290 \mathrm{~J} \mathrm{~m}^{-2} \mathrm{~s}^{-1}{ }^{\circ} \mathrm{C}^{-1}$. This value has been chosen to give best agreement with $F_{\mathrm{C}}$ and $F_{\mathrm{L}}$ in the interval $2 \frac{1}{2}-5 \frac{1}{2} \mathrm{~h}$ (see Fig. B1). This is probably a more accurate way to fix the constant than extrapolating the direct calibration runs to small $\left(T_{\mathrm{f}}-T_{\mathrm{i}}\right)$, though it is in reasonable agreement with the latter procedure. Also shown are the points corresponding to the calculated conductive flux through the eutectic layer, transferred from Fig. B1. The agreement is quite good, for times both inside and outside the 'calibration' interval, though the fluxes appear to diverge early in the experiment, in a manner which can readily be accounted for by a small systematic overestimate of the thickness during this period. A detailed discussion of this last point is hardly justified here; it suffices to say that the fluxes $F_{\mathrm{C}}$ and $F_{\mathrm{R}}$ can be brought into exact agreement by adjustments to the measured mean thickness of the eutectic layer of order $1 \mathrm{~mm}$ or less, which are well within our experimental uncertainty at small thicknesses. 


\section{APPENDIX C}

\section{C.1. Cooling theory}

We present here a quantitative model for the cooling from above of a fluid of eutectic composition. Because the composition remains constant the model need only incorporate thermal effects. We assess whether significant departures occur from this theory if compositional convection takes place. For a given fixed temperature at the top of the system, $T_{\mathrm{i}}$, the model predicts the thickness of the solid eutectic layer, $a$, and the temperature of both the fluid and solid as functions of time. These results are compared with the experimentally determined ones, though the theoretical and current experimental conditions are not identical in that $T_{\mathrm{i}}$ was not constant throughout the experiments.

The model is 'one-dimensional' and is based on equating the conductive heat flux through the solid layer $F_{\mathrm{C}}$, to the sum of the flux due to latent heat release, $F_{\mathrm{L}}$, and the convective flux from the fluid layer, $F_{\mathrm{T}}$; thus

$$
F_{\mathrm{C}}=F_{\mathrm{L}}+F_{\mathrm{T}} \text {. }
$$

In principle, the conductive flux is determined by solving the heat-conduction equations in the growing eutectic layer. However, numerical integration of these equations, kindly carried out for us by M. G. Worster, indicates that to a high degree of accuracy $F_{\mathrm{C}}$ can be represented by the steadystate conductive flux

$$
F_{\mathrm{C}}=K_{\mathrm{e}}\left(T_{\mathrm{e}}-T_{\mathrm{i}}\right) / a,
$$

where $K_{\mathrm{e}}$ is the thermal conductivity of the solid eutectic and $T_{\mathrm{e}}$ is the eutectic temperature. The flux of latent heat is given by

$$
F_{\mathrm{L}}=\rho_{\mathrm{s}} L \frac{\mathrm{d} a}{\mathrm{~d} t}
$$

where $\rho_{\mathbf{S}}$ is the density of the solid and $L$ is the latent heat. On the assumption that the fluid layer is in a state of turbulent convection, the fluid layer will have a uniform mean temperature 0 in the interior with a thin thermal boundary layer at the top of the layer in which the temperature falls rapidly to the eutectic value $T_{e}$. Such profiles are discussed in Turner (1979), where it is also indicated that the convective flux is given by

$$
F_{\mathrm{T}}=c \rho_{\mathrm{f}} c_{\mathrm{f}}\left[\frac{\alpha g \kappa_{\mathrm{f}}^{2}}{v}\right]^{1 / 3}\left(\theta-T_{\theta}\right)^{4 / 3}
$$

where $c$ is an experimental constant whose value is approximately $0 \cdot 21, \rho_{\mathrm{f}}$ and $c_{\mathrm{f}}$ are the density and specific heat of the fluid, $\alpha$ is the coefficient of expansion, $g$ is the acceleration due to gravity, $\kappa_{\mathrm{f}}$ is the thermal diffusivity of the fluid and $v$ is its kinematic viscosity. The condition for the layer to be turbulent and equation (C4) to be appropriate is that the Rayleigh number, defined by

$$
R a=\alpha g\left(\theta-T_{\mathrm{e}}\right)(H-a)^{3} / \kappa_{\mathrm{f}} v,
$$

is greater than a value of about $10^{6}$, where $H$ is the initial depth of the fluid layer. If the Rayleigh number is somewhat less than $10^{6}$, (C4) would need some modification, while if it dropped below a value of around $10^{3}$, convection would cease entirely. In all our laboratory experiments, however, the Rayleigh number greatly exceeded $10^{6}$ and (C4) is valid.

To determine the two unknown quantities $\theta$ and $a$, two equations are required. The first comes from the overall conservation of heat, obtained by substituting $(\mathrm{C} 2)-(\mathrm{C} 4)$ into $(\mathrm{C} 1)$ to yield

$$
K_{\mathrm{e}}\left(T_{\mathrm{e}}-T_{\mathrm{i}}\right) / a=\rho_{\mathrm{S}} L \frac{\mathrm{d} a}{\mathrm{~d} t}+c \rho_{\mathrm{f}} c_{\mathrm{f}}\left[\alpha g \kappa_{\mathrm{f}}^{2} / v\right]^{1 / 3}\left(0-T_{\mathrm{e}}\right)^{4 / 3} .
$$

The second comes from the heat balance in the fluid layer

$$
(H-a) \frac{\mathrm{d} a}{\mathrm{~d} t}=-c\left[\alpha g \kappa_{\mathrm{f}}^{2} / v\right]^{1 / 3}\left(\theta-T_{c}\right)^{4 / 3} .
$$

To these two equations must be added the initial conditions

$$
a=0 \quad \theta=\theta_{0}, \text { say, at } t=0 .
$$

Equations (C6)-(C9) contain a large number of physical parameters. It is convenient to recast the variables, and equations, in non-dimensional terms in order to determine the minimum number of non-dimensional parameters which describe the system. A temperature scale is given by

$$
\delta T=\theta_{0}-T_{e},
$$


which represents the initial temperature excess of the lower layer over the eutectic temperature. A length scale is given by $H$ and a time scale, $\tau$, can be obtained from the balance expressed by (C7), which indicates that

where

$$
\begin{gathered}
\tau=3 H \delta T^{-1 / 3} / J, \\
J=c\left(\alpha g \kappa_{\mathrm{f}}^{2} / v\right)^{1 / 3} .
\end{gathered}
$$

Non-dimensional variables for temperature $(z)$, layer thickness $(y)$ and time $(\xi)$ can then be defined by

$$
\begin{gathered}
\theta=T_{\mathrm{c}}+\delta T z, \\
a=H y \\
t=\tau \xi .
\end{gathered}
$$$$
\text { and }
$$

Substituting (C13)-(C15) into (C6)-(C9), we obtain

$$
\begin{gathered}
\frac{1}{y}=\beta^{2} \frac{\mathrm{d} y}{\mathrm{~d} \xi}+\gamma z^{4 / 3} \\
(1-y) \frac{\mathrm{d} z}{\mathrm{~d} \xi}=-3 z^{4 / 3} \\
y=0 \quad z=1 \quad \text { at } \quad \xi=0, \\
\beta=\left[\rho_{\mathrm{s}} L H^{2} K_{\mathrm{e}}^{-1}\left(T_{\mathrm{e}}-T_{\mathrm{i}}\right)^{-1} \tau^{-1}\right]^{1 / 2} \\
\gamma=\rho_{\mathrm{f}} c_{\mathrm{f}} J \delta T^{4 / 3} H K_{0}^{-1}\left(T_{0}-T_{\mathrm{f}}\right)^{-1} .
\end{gathered}
$$

and

There are thus two independent, non-dimensional parameters $\beta$ and $\gamma$. Note that all three terms of (C16) are positive, and thus the term on the left-hand side, arising from conduction through the solid layer, must always be important. The two terms of the right-hand side may be of different magnitudes in different regimes, however, and thus it can be that only one of them is important. This would reflect the fact that one of the latent heat (as reflected in the parameter $\beta$ ) or convective fluxes (as reflected in the parameter $\gamma$ ) is negligible in comparison to the other.

The full solution of (C16)-(C18) can be determined only numerically. Solution curves so obtained are shown in Fig. $\mathrm{C} 1$ for four different values of $\beta$ and $\gamma$. The general features of the solutions can be most easily explained in terms of approximate, analytic solutions, which will be discussed first. Somewhat lengthy, but nevertheless straightforward, analysis shows that the form of solutions are best described not in terms of $\beta$ and $\gamma$ separately, but in terms of $\beta$ and $A=\gamma / \beta$. If $A$ is small, the convective flux is negligible and a conduction/latent heat release balance dominates. The third term of $(\mathrm{Cl})$ can be neglected, and an approximate solution is

$$
\begin{gathered}
y=(2 \xi)^{1 / 2} / \beta \\
z=\left\{1-2^{1 / 2} \beta\left[\xi^{1 / 2}+\frac{\beta}{2^{1 / 2}} \ln \left(1-2^{1 / 2} \xi^{1 / 2} / \beta\right)\right]\right\}^{-3} .
\end{gathered}
$$

This solution is valid until the fluid has totally solidified, which is represented by $y=1$. The time to do so, $\xi_{\mathrm{s}}$, is given by

$$
\xi_{\mathrm{S}}=\frac{1}{2} \beta^{2} .
$$

This form of solution is shown in Fig. Cla

If $A$ is of unit magnitude the same form of solution (equation (C22)) results, unless $\beta$ is large.

If both $\beta$ and $\gamma$ are large, a different form of solution can occur, which is similar to that which results for large $A$. In this latter parameter regime, there is an initial, rapid (boundary-layer) response governed by

$$
\begin{gathered}
\frac{1}{y}=\beta^{2} \frac{\mathrm{d} y}{\mathrm{~d} \xi}+\gamma \\
z=1 \\
y=0 \text { at } \xi=0
\end{gathered}
$$



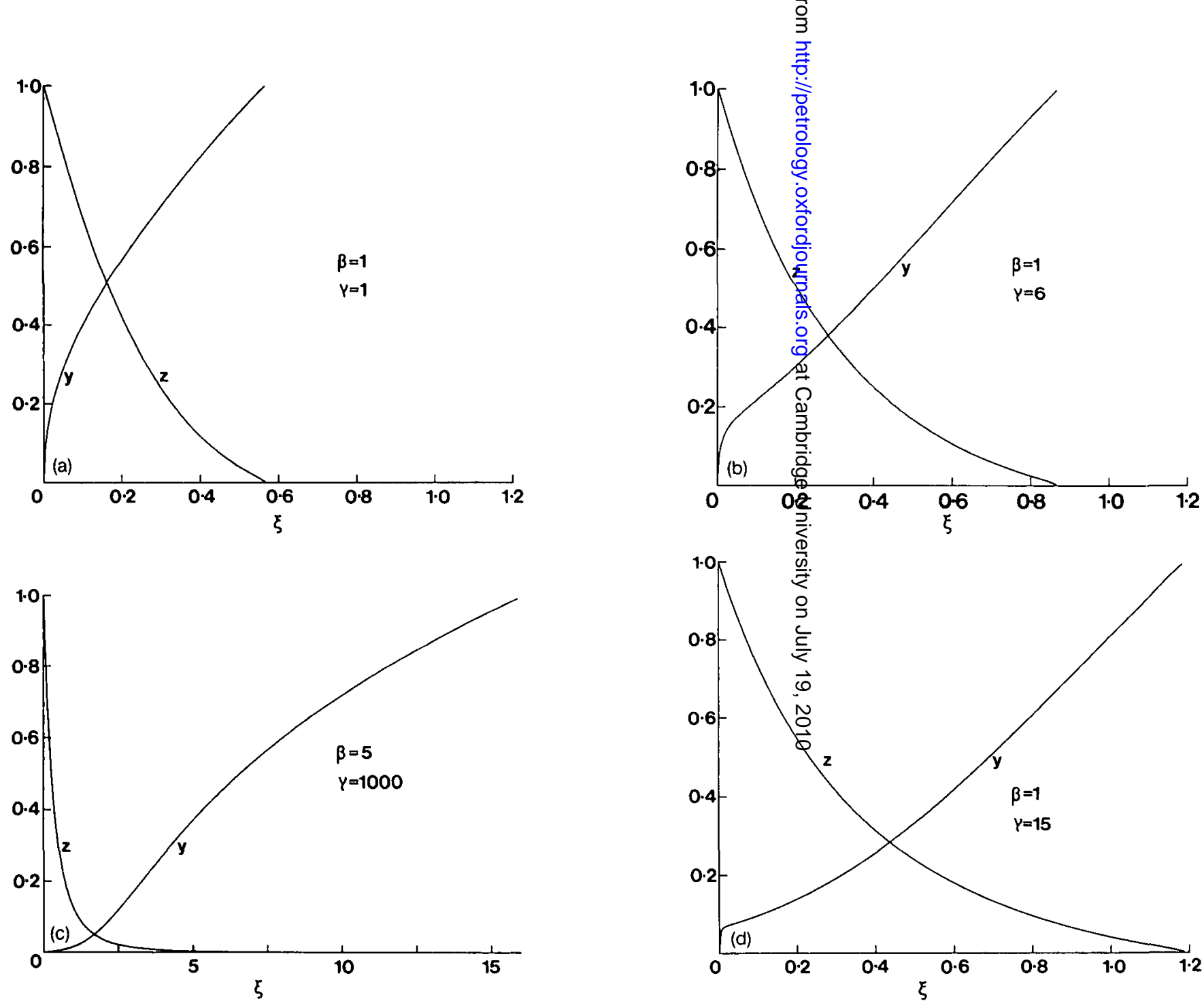

Fig. C1. The non-dimensionalized eutectic layer thickness $y$ and convecting fluid temperature $z$ as functions of time $\xi$. (a) $\beta=1, \gamma=1$ and $A=1$. The dominant balance is between conduction and latent heat release. (b) $\beta=1, \gamma=6$ and $A=6$. (c) $\beta=5, \gamma=1000$ and $A=200$. The initial rapid response in $y$ (too small to be seen on (c)) followed by a dominant balance between conduction and convection which leads to a concave upward form of $y$. After a time convection ceases to be important and $y$ becomes concave downwards. (d) $\beta=1, \gamma=15$ and $A=15$. The dominant balance is between conduction and convection right up to the solidification point. 


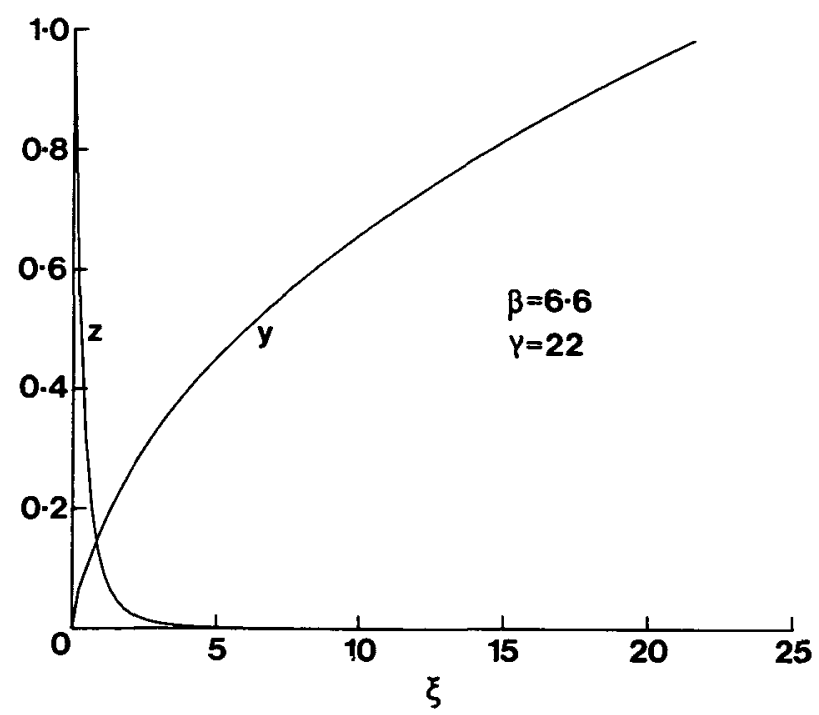

FIG. C2. The non-dimensionalized eutectic layer thickness $y$ and convecting fluid temperature $z$ as functions of time $\xi$ for the experimental parameter values $\beta=6 \cdot 6, \gamma=22$ and $A=3 \cdot 3$.

which extends over a time $A^{-2}$. Thereafter the second term in (C24) is negligible and the solution is given implicitly by

$$
\begin{gathered}
y=\gamma^{-1} z^{-4 / 3} \\
\xi=z^{-1 / 3}-\frac{1}{5} \gamma^{-1} z^{-5 / 3}-1+\frac{1}{5} \gamma^{-1} .
\end{gathered}
$$

This remains valid until the second term of $(\mathrm{C} 16)$ becomes comparable to the third, which occurs when $\xi \approx A^{1 / 7}$. Thereafter, the third term becomes unimportant and the solution reverts to $y$ being proportional to the square root of time. Thus, initially both convection and latent heat release are important, then only convection, and finally only latent heat. This form of solution is shown in Fig. C1b and $\mathrm{Clc}$. It is possible that solidification is complete before convection becomes of negligible importance; such a solution is depicted in Fig. Cld. Latent heat release is then only important in the very earliest stages of the solution.

Curves of the solidification time $\xi_{\mathrm{s}}$ as a function of $\gamma$ are graphed in Fig. C2 for seven values of $\beta$. On the same Figure is drawn the formal solidification time for large $A$,

$$
\frac{4}{5} \gamma^{1 / 4}-1+\frac{1}{5} \gamma^{-1}
$$

which is obtained by determining, from (C27) and (C28), the value of $\xi$ at which $y=1$.

\section{C.2. Comparison between theory and experiment}

The theoretical model is based on the conservation of heat, represented by $(\mathrm{C} 1)$, and the constancy of the top temperature $T_{\mathrm{i}}$. Solution of the resulting equations then leads to the predictions shown graphically in Fig. $\mathrm{C} 1$ and $\mathrm{C} 2$. Ideally, one would conduct a series of experiments with constant $T_{\mathrm{i}}$ over a range or $\beta$ and $\gamma$ which would confirm (C1) and cover the different forms of solutions displayed in Fig. $\mathrm{C} 1$. We were not able to achieve all these aims for several reasons. As explained above, the heat capacity of the cooler was not sufficiently large to allow $T_{\mathrm{i}}$ to be held constant. Further, it is difficult in the laboratory to vary the parameters sufficiently to cover adequately the range of $\beta$ and $\gamma$ for which the theory has been developed. Nevertheless it will be shown below that the theory does describe the overall form and timescale of our experimental results.

Table Cla gives the meaning of the symbols, and Table $\mathrm{Cl} b$ records the values of the parameters used in the experimental run $\mathrm{G}$. The initial time, at which the formation of the eutectic layer begins, has been set at $27 \mathrm{~min} 30 \mathrm{~s}$. Instead of trying to modify the theory to take the variation of $T_{\mathrm{i}}$ strictly into 


\section{TABLE Cla}

Explanation of symbols; their values are given in Tables $\mathrm{Cl} \mathrm{b}$ and $\mathrm{Cl}$.

\begin{tabular}{|c|c|}
\hline \multicolumn{2}{|l|}{ Roman letters } \\
\hline$A=x / \beta$ & $\begin{array}{l}\text { parameter representing ratio of convective flux to latent heat } \\
\text { release }\end{array}$ \\
\hline$c_{\mathbf{F}}$ & specific heat of fluid. \\
\hline$c_{\mathrm{s}}$ & specific heat of solid. \\
\hline$\dot{H}$ & initial thickness of fluid layer. \\
\hline$J$ & multiplicative constant in convective $4 / 3$ flux relationship. \\
\hline$L$ & latent heat of solidification. \\
\hline$T_{\mathrm{e}}$ & eutectic temperature. \\
\hline$T_{\mathrm{i}}$ & fixed temperature at top of system. \\
\hline \multicolumn{2}{|l|}{ Greek letters } \\
\hline$\alpha$ & coefficient of thermal expansion. \\
\hline$\beta$ & parameter expressing the strength of the latent heat release. \\
\hline & parameter expressing the strength of the convective flux. \\
\hline$\delta T=\theta_{\mathrm{o}}-T_{\mathrm{c}}$ & $\begin{array}{l}\text { difference between initial temperature of fluid layer and } \\
\text { eutectic temperature. }\end{array}$ \\
\hline$\theta_{\mathrm{o}}$ & initial temperature of fluid layer. \\
\hline$\kappa_{F}$ & thermal diffusivity of fluid. \\
\hline$\kappa_{\mathrm{S}}$ & thermal diffusivity of solid. \\
\hline$v$ & kinematic viscosity. \\
\hline$\rho_{\mathrm{F}}$ & density of fluid. \\
\hline$\rho_{\mathrm{S}}$ & density of solid. \\
\hline$\tau$ & time scale \\
\hline
\end{tabular}

\section{TABLE Cl $b$}

Physical parameters for experimental run $G$

\begin{tabular}{|c|c|c|}
\hline & & \\
\hline$\rho_{\mathrm{F}}=1066 \mathrm{Kg} \mathrm{m}^{-3}$ & $L=3.4 \times 10^{5} \mathrm{~J} \mathrm{Kg}^{-1}$ & $c_{\mathrm{F}}=3.9 \times 10^{3} \mathrm{~J} \mathrm{Kg}^{-1{ }^{\circ} \mathrm{C}^{-1}}$ \\
\hline$\alpha=2.14 \times 10^{-4}{ }^{\circ} \mathrm{C}^{-1}$ & $\kappa_{\mathrm{F}}=1.3 \times 10^{-7} \mathrm{~m}^{2} \mathrm{~s}^{-1}$ & $v=2.3 \times 10^{-6} \mathrm{~m}^{2} \mathrm{~s}^{-1}$ \\
\hline $\begin{array}{l}\rho_{\mathrm{s}}=978 \mathrm{Kg} \mathrm{m}^{-3} \\
T=-2 \cdot 1^{\circ} \mathrm{C}\end{array}$ & $c_{\mathrm{S}}=1.9 \times 10^{3} \mathrm{~J} \mathrm{Kg}^{-10}{ }^{\circ} \mathrm{C}^{-1}$ & $\kappa_{\mathrm{s}}=1.01 \times 10^{-6} \mathrm{~m}^{2} \mathrm{~s}^{-1}$ \\
\hline $\begin{aligned} T_{c} & =-2.1 \\
J & =5.22 \times 10^{-5} \mathrm{~m} \mathrm{~s}^{-1{ }^{\circ}} \mathrm{C}^{-1 / 3}\end{aligned}$ & & \\
\hline $\begin{array}{l}T_{i}=-15.5^{\circ} \mathrm{C} \\
\theta_{0}=11.3^{\circ} \mathrm{C}\end{array}$ & & \\
\hline $\begin{array}{l}\theta_{0}=11.3^{\circ} \mathrm{C} \\
\tau=1.94 \times 10^{3} \mathrm{~s}\end{array}$ & & $\delta T=13.4{ }^{\circ} \mathrm{C}$ \\
\hline$\beta=6.61$ & $\gamma=21.9$ & $A=3.32$ \\
\hline
\end{tabular}

\section{TABLE Clc}

Typical physical parameters for a komatiite lava

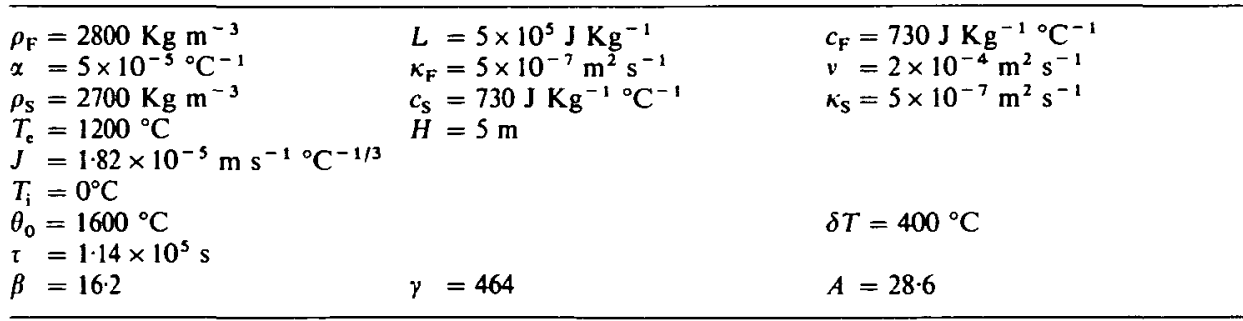




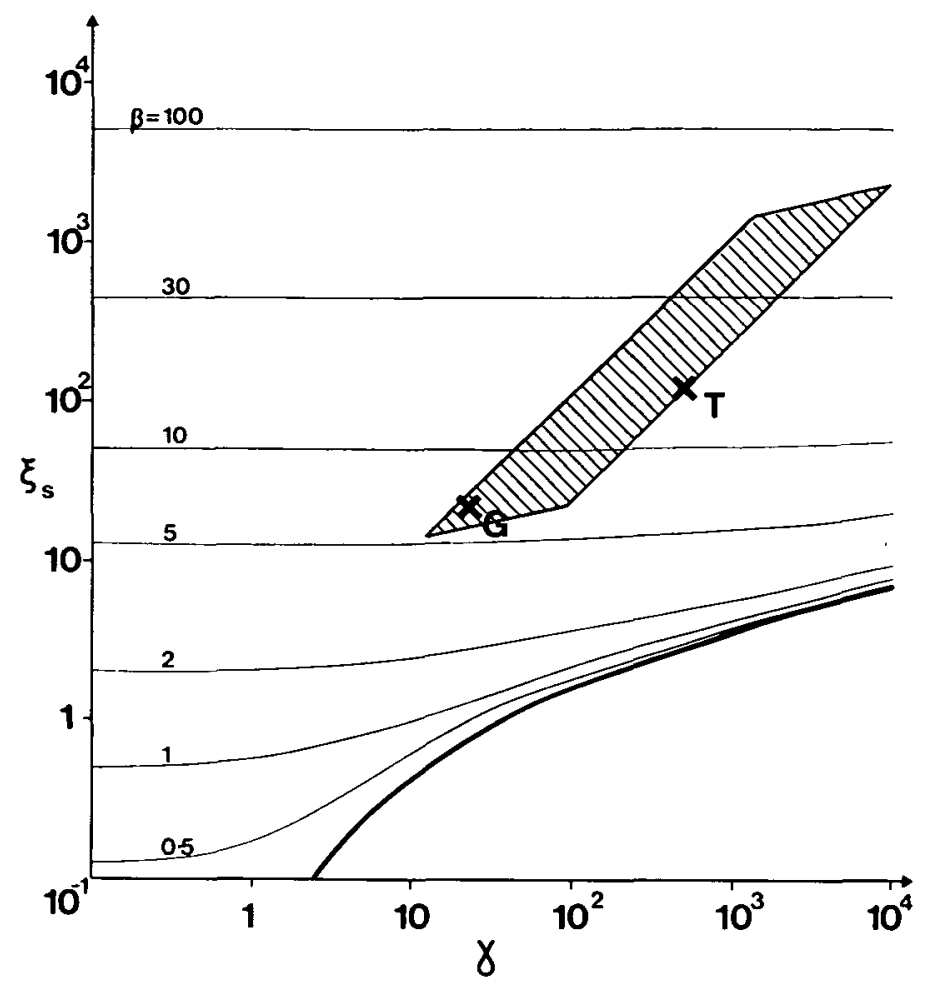

FIG. C3. Curves of the solidification time as functions of $\gamma$ for various values of $\beta$. Also plotted is the asymptotic curve (29) valid for large $\gamma$. The hatched area depicts the probable range of komatiite lavas. $G$ marks the point of experimental run $\mathrm{G}$, with physical parameters as laid out in Table $\mathrm{Cl} a$, and $T$ the point of a typical komatiite lava with the parameters in Table $\mathrm{Cl} b$.

account, we have assumed $T_{\mathrm{i}}=15.5^{\circ} \mathrm{C}$, the mean value over the period $1 \frac{1}{2}-4 \mathrm{~h}$ where it is most nearly constant. Inserting the tabulated values into $(\mathrm{C} 19)$ and $(\mathrm{C} 20)$ gives $\beta=6 \cdot 6, \gamma=22, A=3 \cdot 3$, and the theoretical solution corresponding to these values expected is shown in Fig. C2. Theory predicts that in this parameter range the convective flux will be significant in the earliest part of the experiment (over a time comparable with $\tau=33 \mathrm{~min}$ ), but at later times it will become negligible. This overall flux balance is indeed confirmed by the measurements presented in Fig. B1, and the general forms of the thickness and temperature predicted in Fig. $\mathrm{C} 2$ are consistent with Fig. 11 . The dimensionless timescale for complete solidification is $\xi_{\mathrm{s}}=\frac{1}{2} \beta^{2}=21.7$, which implies a time of $t=21.7 \tau=11.8 \mathrm{~h}$, and this again is in excellent agreement with the laboratory measurement.

\section{C.3. Application to lavas}

The numerical approach described above can now be applied to the cooling of lavas. The theory is strictly valid only for the cooling of eutectic compositions. As discussed in the main text, the calculations should be valid for interpreting the initial stages of cooling before a substantial layer of spinifex has developed beneath the roof.

Table $\mathrm{Cl} c$ represents typical parameters for a cooling komatiite. The values of $\gamma$ and $\beta$ are comparable to the laboratory experiment showing that convective effects would be important in the early stages of cooling. The main parameters that can vary in a komatiite lava are emplacement thickness, $H$, which might range from less than $1 \mathrm{~m}$ to over $100 \mathrm{~m}$ and emplacement temperature which might vary from over $1600^{\circ} \mathrm{C}$ to less than $1300^{\circ} \mathrm{C}$ depending on the extent of cooling during flow. Using these ranges of values the values of $\gamma$ and $\beta$ define the shaded area in Fig. C3.

Full numerical analyses were performed assuming an initial emplacement temperature of $1600{ }^{\circ} \mathrm{C}$, for lava depths of 1,10 and $100 \mathrm{~m}$. The variation of viscosity with temperature was incorporated into the solutions using equation (3) in Part I. Other constant physical parameters were listed in Table C1b. 


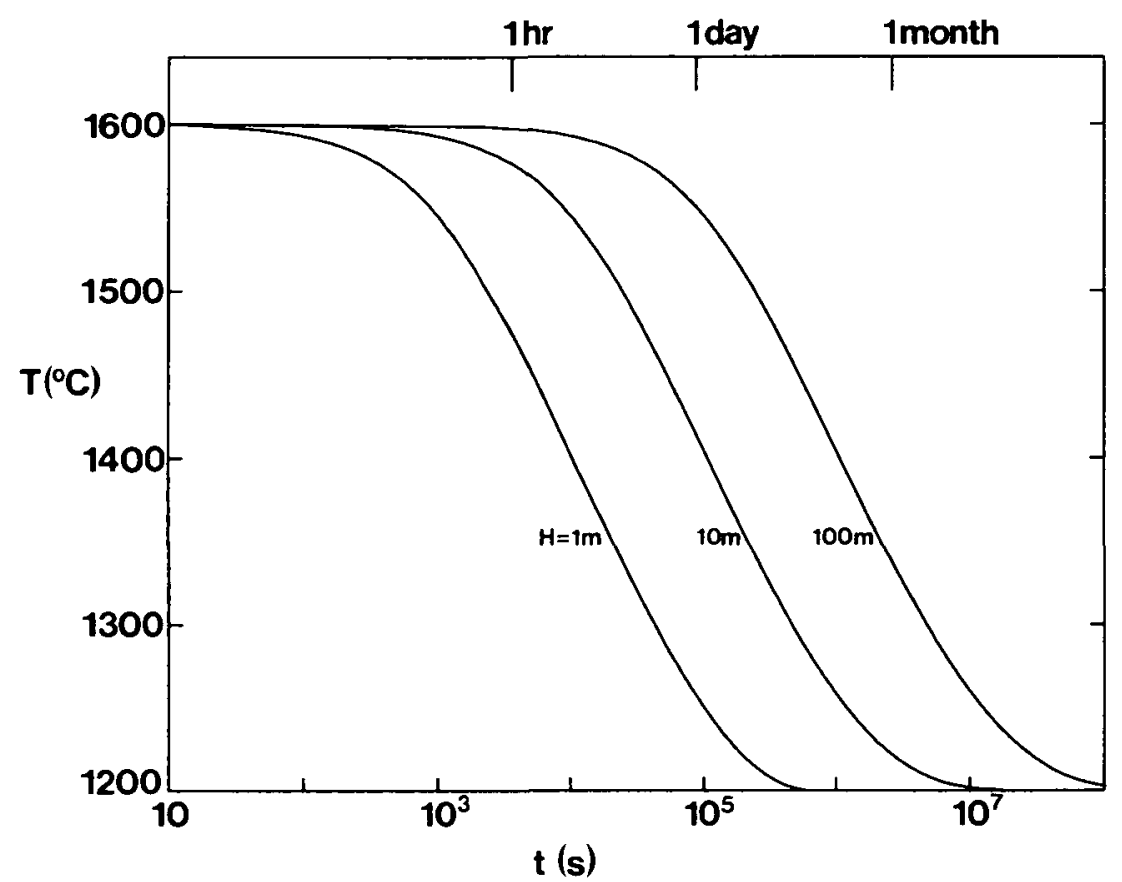

FiG. C4. The temperature as a function of time of ponded komatiite lavas cooled from above of thicknesses 1,10 and $100 \mathrm{~m}$ (the same cases considered in Fig. 13).

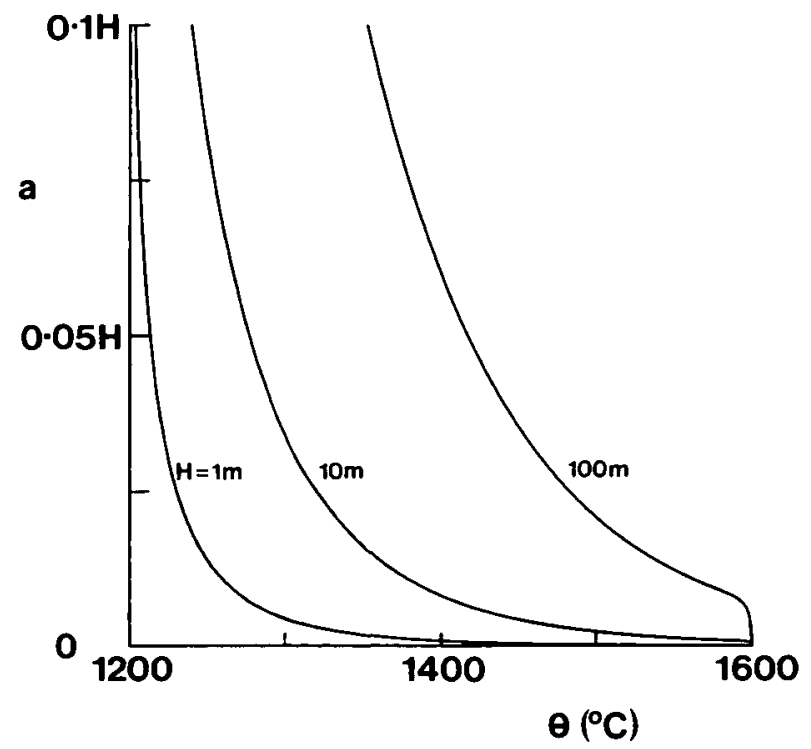

FIG. C5. The thickness of the crust as a function of temperature for the cases considered in Fig. C4. 
Figure $\mathrm{C} 4$ shows the variations of temperature with time for the three lava depths. In all cases there is a rapid decrease in lava temperature with time which is dominated by convection. Substantial temperature loss in the interior occurs while the upper crust remains thin. We emphasize that in a non-eutectic fluid, the variation of temperature with time will increasingly deviate from those shown in Fig. $\mathrm{C} 4$ as the spinifex develops and insulates the flow interior. Figure 13 in the main text shows the variation of initial cooling rate with lava flow thickness for a $1600^{\circ} \mathrm{C}$ lava. The corresponding results for the thickness of the conducting upper crust as a function of temperature are shown in Fig. C5.

These calculations can be usefully compared with those presented by Usselman et al. (1979) who based their calculations on a conductive model. For an initial temperature of $1500^{\circ} \mathrm{C}$, flow depth $60 \mathrm{~m}$ and country rock with a conductivity of $0.050 \mathrm{cal} \mathrm{cm}-1 \mathrm{~s}^{-1}{ }^{\circ} \mathrm{C}^{-1}$, they calculated only a $10^{\circ} \mathrm{C}$ temperature drop in the centre of the flow and an upper and lower crust (defined as rock below $1200^{\circ} \mathrm{C}$ ) of several metres thickness after a period of 73 days. In the model presented here the central lava temperature would have decreased by about $250^{\circ} \mathrm{C}$ while the thickness of the upper crust would be about $5 \mathrm{~m}$. These contrasts highlight the point that substantial cooling of interior komatiite lavas will take place in the initial stages because of convection. Conductive models are inappropriate for the early stages of cooling. 